\title{
The Effects of a Money-Financed Fiscal Stimulus
}

\author{
Jordi Galí * \\ CREI, Universitat Pompeu Fabra and Barcelona GSE
}

July 2019

\begin{abstract}
I analyze the effects of a money-financed fiscal stimulus and compare them with those resulting from a conventional debt-financed stimulus. I study the effects of both a tax cut and an increase in government purchases, with and without a binding zero lower bound (ZLB) on the nominal interest rate. When the ZLB is not binding, a moneyfinanced fiscal stimulus is shown to have much larger multipliers than a debt-financed fiscal stimulus. That difference in effectiveness persists, but is much smaller, under a binding ZLB. Nominal rigidities are shown to play a major role in shaping those effects.

Keywords: Seignorage, government spending, fiscal multipliers, helicopter drop JEL codes: E32, E52, E62
\end{abstract}

*I have benefited from comments by seminar and conference participants at the NBER Summer Institute, Dutch Central Bank, Sveriges Riksbank, Stanford University, San Francisco Fed, IMF, Federal Reserve Board, ECB, University of Bern, Banco de España, LUISS, Banca d'Italia, CEPREMAP-Banque de France-Collège de France, and Deutsche Bundesbank, as well as an anonymous referee. Davide Debortoli was most helpful with the programming. I thank Cristina Manea and Alain Schlaepfer for excellent research assistance. Funding from CERCA Programme/Generalitat de Catalunya and the Barcelona GSE through a Severo Ochoa grant is gratefully acknowledged. 


\section{Introduction}

The recent economic and financial crisis has acted as a powerful reminder of the limits to conventional countercyclical policies. The initial response of monetary and fiscal authorities to the decline of economic activity, through rapid reductions in interest rates and substantial increases in structural deficits, left policymakers out of conventional ammunition well before the economy had recovered. Policy rates hit their zero lower bound (ZLB) at a relatively early stage of the crisis, while large and rising debt ratios forced widespread fiscal consolidations that likely delayed the recovery and added to the economic pain.

Against that background, and looking ahead, there is a clear need to think of policies that may help stimulate a depressed economy without relying on lower nominal interest rates (which are unfeasible when the zero lower bound is binding) or further rises in the stock of government debt (given the high debt ratios - with the consequent risks of a debt crisis- that often characterize depressed economies). In that regard, proposals focusing on labor cost reductions or structural reforms, repeatedly put forward by the IMF and other international organizations, have been recently called into question by several authors on the grounds that their effectiveness at raising output hinges on a simultaneous loosening of monetary policy, an option no longer available under a binding ZLB. ${ }^{1}$

In the present paper I analyze the effectiveness of an alternative policy: a money-financed fiscal stimulus. As discussed below, that stimulus requires neither an increase in the stock of government debt nor higher taxes, current or future, and hence it overcomes some of the hurdles facing a conventional fiscal stimulus. Despite these apparent virtues, the money-financing alternative can seldom be found in policy or academic discussions of policies that may help stimulate the economy. ${ }^{2}$ Below I study separately two types of money-financed fiscal stimuli: a reduction in (lump-sum) taxes and an increase in government purchases. For each of these interventions, I analyze its effects on several macro variables, and compare them to the corresponding effects from a more conventional debt-financed fiscal stimulus.

Each of these policy interventions and their effects is analyzed in the context of two alternative environments. In the baseline environment (which I refer to below as "normal times"), the fiscal stimulus is exogenous, and the ZLB on the nominal interest rate is assumed not to be binding throughout the intervention. In the alternative environment (labeled as "liquidity trap"), the stimulus is assumed to take place in response to an adverse demand shock that brings the natural interest rate into negative territory, thus preventing monetary policy from fully stabilizing output and inflation, due to the ZLB.

The goal of the present paper is not so much to offer a realistic quantitative analysis of the effects of a money-financed fiscal stimulus, but to get a better understanding of its qualitative implications -especially in comparison to a fiscal stimulus financed through more orthodox arrangements- and of the consequences of its implementation under a binding ZLB. With this in mind, I conduct the analysis below using a textbook New Keynesian model with monopolistic

\footnotetext{
${ }^{1}$ See Eggertsson, Ferrero and Raffo (2014), Galí (2013), Galí and Monacelli (2016), and Galí and Billi (2018), among others.

${ }^{2}$ As argued by Turner (2013) "...the prohibition of money financed deficits has gained within our political economy the status of a taboo, as a policy characterised not merely as -in many circumstances and on balanceundesirable, but as something we should not even think about let alone propose..." The present paper seeks to contribute to the breaking of that taboo.
} 
competition and sticky prices. For simplicity I restrict the analysis to a closed economy with no endogenous capital accumulation. Ultimately, the paper's objective is to provide a formal analysis, in the context of a specific model, that clarifies the mechanisms behind the "helicopter drop" interventions that occasionally emerge in the policy debate, but which are, generally, discussed in rather imprecise terms.

The main findings of the paper can be summarized as follows. In normal times, when the ZLB is not binding, a money-financed fiscal stimulus is shown to have much larger output multipliers than a debt-financed fiscal stimulus. The main reason for that difference lies in the monetary accommodation associated with the former type of intervention, which leads to a large positive response of (private) consumption. Under debt financing, on the other hand, a fiscal stimulus has either no effect on activity (in the case of a tax cut) or a much smaller effect than under money-financing (in the case of an increase in government purchases), due to the endogenous tightening of monetary policy that accompanies it under the assumption that the central bank follows an inflation targeting strategy. Conditional on money-financing, an increase in government purchases is shown to have a larger output multiplier, but a smaller consumption multiplier, than a tax cut.

Under a binding zero lower bound, the difference in effectiveness between a money-financed fiscal stimulus and a debt-financed one persist, though it is smaller in the case of an increase in government spending. Likewise, the differences between a money-financed tax cut and a money-financed increase in government spending become smaller in a liquidity trap.

My analysis stresses the key role of nominal rigidities in generating the previous findings. In the limiting case, with flexible prices (and given Ricardian equivalence), the response of aggregate output to a fiscal stimulus is not affected by the path of the money supply or the nominal interest rate, and hence it is independent of the extent to which the fiscal stimulus is money-financed.

The remainder of the paper is organized as follows. Section 2 discusses the related literature. Section 3 describes formally the fiscal and monetary framework used in the subsequent analysis, as well as the specific experiments undertaken. Section 4 describes the (standard) nonpolicy blocks of the model. Section 5 derives the (approximate) equilibrium conditions in a neighborhood of the perfect foresight steady state. Section 6 analyzes the effect of an exogenous tax cut and an exogenous increase in government purchases, in the absence of a binding ZLB constraint, and under the two financing regimes considered. Section 7 evaluates the effects of identical fiscal interventions when the economy is hit by an adverse shock that makes the ZLB temporarily binding. Section 8 summarizes the main findings and concludes.

\section{$2 \quad$ Related Literature}

Milton Friedman's celebrated "monetary and fiscal framework" article (Friedman, 1948) is, as far as I know, the earliest reference in which a case for money-financed budget deficits is made. In Friedman's view, the ideal policy framework would require that governments maintain a balanced budget in structural terms (i.e. under full employment), but that they let automatic stabilizers operate in the usual way, with the deficits generated during recessions being financed by issuing money and, symmetrically, with surpluses in boom times used to reduce the money stock. Such a "rule" would be a most effective countercyclical tool for, in the words of Friedman, 
"...in a period of unemployment [issuing interest-earning securities] is less deflationary than to levy taxes. This is true. But it is still less deflationary to issue money. " A similar argument can be found in Haberler (1952), who emphasizes how the effectiveness of such a policy would be amplified through the Pigou effect channel. ${ }^{3}$

Friedman (1969), in the context of his analysis of optimal policy, represents the earliest known reference to "helicopter money," a term often used to refer to money-financed fiscal transfers. More specifically, Friedman sought to trace the effects of a thought experiment whereby "one day a helicopter flies over this community and drops an additional \$1,000 in bills from the sky...," though no endorsement of that policy was intended.

More recently, Bernanke (2003) refers to the potential desirability of a money-financed fiscal stimulus, in the context of a discussion of the options left to Japanese policy makers during the liquidity trap episode experienced in that economy. The same motivation was shared in the subsequent work by Auerbach and Obstfeld (2005), using an analytical approach closer to the present paper. More specifically, their paper studies the effectiveness of open market operations in raising inflation and output when the economy is at the zero lower bound, as a result of some temporary adverse shock. That effectiveness is shown to be strongly dependent on whether the increase in liquidity is permanent and expected to be so by agents. Their analysis and some of the qualitative findings are related to those of the intervention considered in section 5 below, namely, a tax cut funded by money creation under a binding ZLB. A related, more recent contribution can be found in Buiter (2014), who analyzes the impact of a money-financed transfer to households (a "helicopter drop") in a relatively general setting, emphasizing the importance of "irredeemability" of money as the ultimate source of the expansionary effect on consumption of a such a policy. The present paper can be viewed as extending the analyses in Auerbach and Obstfeld (2005) and Buiter (2014) by providing a comparison of the effects of money-financed vs. debt-financed tax cuts, as well as an analysis of the differential effects of money-financed tax cuts vs. money-financed increases in government purchases. ${ }^{4}$

Other recent discussions include Turner $(2013,2016)$ who points to the potential virtues of monetary financing of fiscal deficits. See also Reichlin, Turner and Woodford (2013) and Giavazzi and Tabellini (2014) for related discussions. The analyses in those works is not, however, based on a formal model. ${ }^{5}$

The present paper is also related to the literature on monetary policy design in the presence

\footnotetext{
${ }^{3}$ Haberler (1952) describes the policy intervention he has in mind as follows: "Suppose the quantity of money is increased by tax reductions or government transfer payments, government expenditures remaining unchanged and the resulting deficit being financed by borrowing from the central bank or simply by printing money. The wealth-saving theorem tells us that, aprt from the operation of the Keynes effect (through the rate of interest), consumption and investment will increase when the quantity of money grows. I find it difficult to believe that this may not be so."

${ }^{4}$ The papers also differ in terms of modelling choices. Thus, Auerbach and Obstfeld (2005) use a flexible price model as their baseline framework, turning to a model with Taylor contracts as their sticky price model. They generate a demand for money by assuming a cash-in-advance constraint, thus implying a constant velocity. Finally they introduce taxation in the form of (distortionary) consumption taxes. By contrast, I adopt as a reference framework a textbook New Keynesian model with Calvo pricing, money in the utility function, and lump-sum taxes. With the exception of the treatment of the financing of fiscal stimulus, my framework corresponds to the workhorse model generally used in the recent monetary policy literature.

${ }^{5}$ A recent working paper by Bilbiie and Ragot (2017) discusses the role of "helicopter drops" (vs open market operations) as an insurance device in the context of an analysis of optimal monetary policy in a model with heterogeneous agents and incomplete markets.
} 
of a ZLB. In particular, the papers by Jung, Teranishi and Watanabe (2003), Eggertsson and Woodford (2003) and Werning (2011), study optimal policy in an environment similar to the one analyzed in section 7 below: the case of a fully unanticipated, once-and-for-all adverse shock to the natural rate, which makes the latter temporarily negative.

The present paper is also related to the large literature on the effects of changes in government purchases. ${ }^{6}$ Much of that literature has tended to focus on the size of the government spending multiplier under alternative assumptions. That multiplier is predicted to be below or close to unity in the context of standard RBC or New Keynesian models, but it can rise substantially above one under a variety of assumptions, including the presence of hand-to-mouth consumers (see, e.g., Galí, López-Salido and Vallés (2007)), a binding ZLB constraint (e.g., Christiano, Eichenbaum and Rebelo (2011), Eggertsson (2011)), non-separable utility in consumption and hours (e.g. Bilbiie (2011)), and a policy regime characterized by an active fiscal policy and a passive monetary policy (e.g. Davig and Leeper (2011)). The present paper shows that large multipliers also arise when the increase in government purchases is financed through money creation, even if none of the above assumptions hold.

\section{The Fiscal and Monetary Policy Framework}

Next I describe the fiscal and monetary policy framework assumed in subsequent sections. I start by introducing the consolidated budget constraint of the fiscal and monetary authorities, and then move on to describe the policy interventions that are the focus of my analysis. Throughout I consider a fully unanticipated intervention which is announced at a given point in time (period 0 ). No other news or shock are assumed to occur after that, so the environment is modeled as a deterministic one.

\subsection{Government: Budget Constraints and Financing Regimes}

The government -henceforth understood as combining the fiscal and monetary authorities, acting in a coordinated way- is assumed to finance its expenditures through three sources: (i) lump-sum taxes $\left(T_{t}\right)$, (ii) the issuance of nominally riskless one-period bonds $\left(B_{t}\right)$ with a nominal yield $i_{t}$, and (iii) the issuance of (non-interest bearing) money $\left(M_{t}\right)$. The government's consolidated budget constraint is thus given by:

$$
P_{t} G_{t}+B_{t-1}\left(1+i_{t-1}\right)=P_{t} T_{t}+B_{t}+\Delta M_{t}
$$

where $G_{t}$ denotes (real) government purchases. Equivalently, and after letting $\mathcal{B}_{t} \equiv B_{t} / P_{t}$ and $\mathcal{R}_{t} \equiv\left(1+i_{t}\right)\left(P_{t} / P_{t+1}\right)$ denote respectively real debt outstanding and the (ex-post) gross real interest rate, one can write:

$$
G_{t}+\mathcal{B}_{t-1} \mathcal{R}_{t-1}=T_{t}+\mathcal{B}_{t}+\Delta M_{t} / P_{t}
$$

where $\Delta M_{t} / P_{t}$ represents period $t$ 's seignorage, i.e. the purchasing power of newly issued money.

\footnotetext{
${ }^{6}$ Woodford (2011) uses a framework identical to the one used in the present paper to analyze the effects of increases in government purchases and the role played by monetary policy in shaping those effects. See Ramey (2011) for a broad survey of the theoretical and empirical literature on the subject.
} 
With little loss of generality given the paper's objectives, the analysis below focuses on equilibria near a steady state with zero inflation, no trend growth, and constant government purchases $G$, taxes $T$ and government debt $\mathcal{B}$. Constancy of real balances requires that $\Delta M=0$ and, hence, zero seignorage in that steady state. It follows from (2) that

$$
T=G+\rho \mathcal{B}
$$

must hold in that steady state, using the fact that, as shown below, $\mathcal{R}=1+\rho$, where $\rho$ is the household's discount rate.

In a neighborhood of that steady state, the level of seignorage, expressed as a fraction of steady state output, can be approximated as

$$
\begin{aligned}
\left(\Delta M_{t} / P_{t}\right)(1 / Y) & =\left(\Delta M_{t} / M_{t-1}\right)\left(P_{t-1} / P_{t}\right) L_{t-1} / Y \\
& \simeq \varkappa \Delta m_{t}
\end{aligned}
$$

where $L_{t} \equiv M_{t} / P_{t}$ denotes real balances, $m_{t} \equiv \log M_{t}$, and $\varkappa \equiv L / Y$ is the inverse income velocity of money, evaluated at the steady state. In other words, up to a first order approximation, the level of seignorage is proportional to money growth, a result that will be used below.

Let $\widehat{b}_{t} \equiv\left(\mathcal{B}_{t}-\mathcal{B}\right) / Y, \widehat{g}_{t} \equiv\left(G_{t}-G\right) / Y$, and $\widehat{t}_{t} \equiv\left(T_{t}-T\right) / Y$ denote, respectively, deviations of government debt, government purchases, and taxes from their steady state values, expressed as a fraction of steady state output. In what follows I interpret $\mathcal{B}$ as an exogenously given long run debt target (denoted by $b \equiv \mathcal{B} / Y$ when expressed as a share of steady state output).

A first order approximation of the consolidated budget constraint (2) around the zero inflation steady state yields the following difference equation describing the evolution of government debt, expressed as a share of steady state output $Y$ :

$$
\left.\widehat{b}_{t}=(1+\rho) \widehat{b}_{t-1}+b(1+\rho) \widehat{i}_{t-1}-\pi_{t}\right)+\widehat{g}_{t}-\widehat{t}_{t}-\varkappa \Delta m_{t}
$$

where $\pi_{t} \equiv \log \left(P_{t} / P_{t-1}\right)$ denotes inflation between $t-1$ and $t$ and $\widehat{i}_{t} \equiv \log \left(\left(1+i_{t}\right) /(1+\rho)\right)$.

Throughout I assume a simple tax rule of the form

$$
\widehat{t}_{t}=\psi_{b} \widehat{b}_{t-1}+\widehat{t}_{t}^{*}
$$

Thus, tax variations have two components. The first component, $\psi_{b} \widehat{b}_{t-1}$, is endogenous and varies in response to deviations of the debt ratio from its long run target. The second component, $\widehat{t}_{t}^{*}$, is independent of the debt ratio and should be interpreted as the exogenous component of the tax rule.

Combining (5) and (6) we obtain

$$
\widehat{b}_{t}=\left(1+\rho-\psi_{b}\right) \widehat{b}_{t-1}+b(1+\rho)\left(\widehat{i}_{t-1}-\pi_{t}\right)+\widehat{g}_{t}-\widehat{t}_{t}^{*}-\varkappa \Delta m_{t}
$$

Henceforth I assume $\psi_{b}>\rho$, which combined with $\lim _{T \rightarrow \infty}\left[\widehat{g}_{T}, \widehat{t}_{T}^{*}, \Delta m_{T}, \widehat{i}_{T}, \pi_{T}\right]^{\prime}=0$, guarantees that $\lim _{T \rightarrow \infty} E_{t}\left\{\widehat{b}_{T}\right\}=0$, i.e. the debt ratio converges to its long run target. Accordingly, the government's transversality condition $\lim _{T \rightarrow \infty} \Lambda_{0, T} \mathcal{B}_{T}=0$ will be satisfied for any price level path, as long as the discount factor $\Lambda_{0, T} \equiv \prod_{j=0}^{T-1} \mathcal{R}_{j}^{-1}$ converges to zero as $T \rightarrow \infty$, which is the case in all the experiments considered below. The previous property, often referred to in the literature as Ricardian (or passive) fiscal policy (e.g. Leeper (1991)), is assumed in standard specifications of the New Keynesian model, and must be combined with an active monetary policy (as implicitly assumed below) in order to guarantee a locally unique equilibrium. 


\subsection{Experiments}

Below I analyze two stylized fiscal interventions, using the basic New Keynesian model as a reference framework. The first intervention consists of an exogenous tax cut, while the second one takes the form of an exogenous increase in government purchases. Both interventions are announced in period 0 , and implemented from that period onwards. For concreteness, in the case of a tax cut I assume

$$
\widehat{t_{t}^{*}}=-\delta^{t}<0
$$

for $t=0,1,2, \ldots$ where $\delta \in[0,1)$ measures the persistence of the exogenous fiscal stimulus. Symmetrically, in the case of an increase in government purchases I assume

$$
\widehat{g}_{t}=\delta^{t}>0
$$

for $t=0,1,2, \ldots$ Notice that in both cases the size of the stimulus is normalized to correspond to a 1 percent of steady state output in period 0 .

The effects of each type of fiscal intervention are analyzed under two alternative regimes, that jointly describe how the fiscal stimulus is financed and how monetary policy is conducted. The first regime, which I refer to as money financing (or $M F$, for short) is the main focus of the present paper. I define that regime as one in which seignorage is adjusted every period in order to keep real debt $\mathcal{B}_{t}$ unchanged. In terms of the notation above, this requires $\widehat{b}_{t}=0$ and hence

$$
\Delta m_{t}=(1 / \varkappa)\left[\delta^{t}+b(1+\rho)\left(\widehat{i}_{t-1}-\pi_{t}\right)\right]
$$

for $t=0,1,2, \ldots$ Note that the previous assumptions, combined with (6), imply that under the $M F$ regime taxes need not be adjusted as a result of a increase in government purchases, either in the short run or in the long run, relative to their initial level. On the other hand, in the case of a tax cut, taxes are temporarily lowered by an amount $\delta^{t}$. In other words, under the $M F$ regime, neither taxes nor debt need to be raised in response to the fiscal interventions considered here. In both cases, however, monetary policy has to give up control of the nominal interest rate, instead adjusting the money supply in order to meet the government's financing needs.

Under the second financing scheme considered, which I refer to as debt financing (or $D F$, for short), the fiscal authority issues debt in order to finance the fiscal stimulus, eventually adjusting the path of taxes in order to attain the long run debt target $\mathcal{B}$, as implied by rule (6)). ${ }^{7}$ The monetary authority, on the other hand, is assumed to pursue an independent price stability mandate. For concreteness I assume that, as long as feasible, it conducts policy so that $\pi_{t}=0$ for all $t$. The money supply -and, as a result, seignorage- then adjusts endogenously in order to bring about the interest rate required to stabilize prices, given money demand ${ }^{8}$ I interpret

\footnotetext{
${ }^{7}$ Given that Ricardian equivalence holds, the particular path for debt and lump-sum taxes is irrelevant for the equilibrium values of output and other real variables.

${ }^{8} \mathrm{I}$ am not assuming any particular instrument rule, only that some rule is in place that guarantees price stability (as a unique equilibrium). That outcome could be implemented with an interest rate rule, but also with a money growth rule, both properly designed; but I really don't want to focus here on issues of implementation, which are well understood and orthogonal to the point of the paper (see, e.g. chapter 4 in Galí, 2015). The main qualitative findings reported below are robust to assuming a plausibly calibrated Taylor-type rule, even though that rule imples some deviation from full price stability.
} 
the DF regime as a stylized representation of the one prevailing in most advanced economies, as well as the regime generally assumed (explicitly or implicitly) in the New Keynesian literature on the effects of fiscal policy. ${ }^{9}$

In the baseline scenario described above, the fiscal interventions analyzed are exogenous, and undertaken in the absence of any other disturbance. Furthermore, the nominal interest rate is assumed to remain positive at all times. In Section 7, by contrast, and as discussed in more detail therein, I study the effects of a fiscal stimulus that is triggered in response to an adverse demand shock that pulls the natural rate of interest temporarily into negative territory. In that context the ZLB prevents the monetary authority from attaining its price stability objective. I refer to that scenario as a liquidity trap. I compare the economy's response to the adverse shock with and without a fiscal response in the form of a tax cut or an increase in government purchases. In the case of a fiscal response, I consider both a money financing and a debt financing regime (as described above), and compare their respective outcomes.

\section{Non-Policy Blocks}

Next I describe the non-policy blocks of the model, which I keep as simple as possible, using the basic New Keynesian model as a reference framework. ${ }^{10}$

\subsection{Households}

The economy is inhabited by a large number of identical infinitely-lived households. Household preferences are given by

$$
E_{0} \sum_{t=0}^{\infty} \beta^{t} \mathcal{U}\left(C_{t}, L_{t}, N_{t} ; Z_{t}\right)
$$

where $C_{t}$ denotes consumption, $N_{t}$ is employment, $L_{t} \equiv M_{t} / P_{t}$ denotes household's holdings of real balances, and $Z_{t}$ is an exogenous demand shifter. ${ }^{11} \beta \equiv 1 /(1+\rho) \in(0,1)$ is the discount factor. As usual it is assumed that $C_{t} \geq 0, N_{t} \geq 0$ and $L_{t} \geq 0$ for all $t$.

The household maximizes (9) subject to a sequence of budget constraints

$$
P_{t} C_{t}+B_{t}+M_{t}=B_{t-1}\left(1+i_{t-1}\right)+M_{t-1}+W_{t} N_{t}+D_{t}-P_{t} T_{t}
$$

for $t=0,1,2, \ldots$ where $W_{t}$ is the nominal wage and $D_{t}$ are dividends paid by firms. A standard solvency constraint ruling out Ponzi schemes is assumed:

$$
\lim _{T \rightarrow \infty} \Lambda_{0, T} \mathcal{A}_{T} \geq 0
$$

where $\mathcal{A}_{t} \equiv\left[B_{t-1}\left(1+i_{t-1}\right)+M_{t-1}\right] / P_{t}$ denotes the representative household's real financial wealth at the beginning of period $t$.

\footnotetext{
${ }^{9}$ With the exception of the literature on the fiscal theory of the price level (e.g. Leeper, 1991).

${ }^{10}$ See e.g. Woodford (2003) or Galí (2015) for a textbook exposition.

${ }^{11}$ The preference shifter $Z_{t}$ is used to generate a reduction in the natural rate of interest in the "liquidity trap" scenario analyzed in section 7 .
} 
In the analysis below, period utility $\mathcal{U}(\cdot)$ is assumed to take the form

$$
\mathcal{U}(C, L, N ; Z)=(U(C, L)-V(N)) Z
$$

with $V(\cdot)$ increasing and convex, $U(\cdot)$ increasing and concave, and $h(L / C) \equiv U_{l} / U_{c}$ being a continuous and decreasing function satisfying $h(\bar{\varkappa})=0$ for some $0<\bar{\varkappa}<\infty$. The last assumption, combined with (13) below, guarantees that the demand for real balances remains bounded as the interest rate approaches zero, with a satiation point attained at $L=\bar{\varkappa} C$.

The optimality conditions for the household problem are given by:

$$
\begin{gathered}
U_{c, t}=\beta\left(1+i_{t}\right)\left(P_{t} / P_{t+1}\right) U_{c, t+1} \\
W_{t} / P_{t}=V_{n, t} / U_{c, t} \\
h\left(L_{t} / C_{t}\right)=i_{t} /\left(1+i_{t}\right)
\end{gathered}
$$

for $t=0,1,2, \ldots$ Equation (11) is the consumption Euler equation. Equation (12) is the intratemporal optimality condition, determining labor supply, under the assumption of a competitive labor market. Equation (13) is a money demand schedule. Such optimality conditions must be complemented with the transversality condition $\lim _{T \rightarrow \infty} \Lambda_{0, T} \mathcal{A}_{T}=0$.

\subsection{Firms}

A representative firm produces the single final good with a constant returns technology

$$
Y_{t}=\left(\int_{0}^{1} Y_{t}(i)^{1-\frac{1}{\epsilon}} d i\right)^{\frac{\epsilon}{\epsilon-1}}
$$

where $Y_{t}(i)$ denotes the quantity of intermediate good $i$, for $i \in[0,1]$. Profit maximization under perfect competition leads to the set of demand conditions:

$$
Y_{t}(i)=\left(P_{t}(i) / P_{t}\right)^{-\epsilon} Y_{t} \quad \text { all } i \in[0,1]
$$

Intermediate goods are produced by a continuum of monopolistically competitive firms, indexed by $i \in[0,1]$. Each firm produces a differentiated intermediate good with a technology

$$
Y_{t}(i)=N_{t}(i)^{1-\alpha}
$$

where $N_{t}(i)$ denotes labor input hired by firm $i$.

Each firm in the intermediate goods sector can reset the price of its good with probability $1-\theta$ in any given period, as in Calvo (1983), subject to the isoelastic demand schedule (14). In that case, aggregation of the optimal price setting decisions leads to dynamics of inflation around a zero inflation steady state described by the difference equation:

$$
\pi_{t}=\beta \pi_{t+1}-\lambda\left(\mu_{t}-\mu\right)
$$

where $\mu_{t} \equiv \log \frac{(1-\alpha) P_{t}}{W_{t} N_{t}^{\alpha}}$ is the (log) average price markup, $\mu \equiv \log \mathcal{M}=\log \frac{\epsilon}{\epsilon-1}>0$ is the (log) desired price markup, and $\lambda \equiv \frac{(1-\theta)(1-\beta \theta)(1-\alpha)}{\theta(1-\alpha+\alpha \epsilon)} \cdot{ }^{12}$ I interpret $\theta \in[0,1]$, the fraction of firms keeping their price constant in any given period, as an index of price rigidities.

\footnotetext{
${ }^{12}$ See, e.g. Galí (2015, chapter 3) for a derivation.
} 


\section{$5 \quad$ Steady State and Equilibrium Dynamics}

The analysis below considers equilibria in a neighborhood of a steady state with zero inflation and zero government purchases. ${ }^{13}$ Note that at the zero inflation steady state price markups must be at their desired level. Combining that result with (12), (13) and the goods market equilibrium condition, $Y_{t}=C_{t}+G_{t}$, all evaluated at the steady state (with $G=0$, for simplicity), one can derive the conditions jointly determining steady state output and real balances, which are given by the system

$$
\begin{gathered}
(1-\alpha) U_{c}\left(N^{1-\alpha}, L\right)=\mathcal{M} V_{n}(N) N^{\alpha} \\
h\left(L / N^{1-\alpha}\right)=\rho /(1+\rho)
\end{gathered}
$$

which is assumed to have a unique solution. ${ }^{14}$

Letting $\widehat{y}_{t} \equiv \log \left(Y_{t} / Y\right), \widehat{c}_{t} \equiv \log \left(C_{t} / C\right), \widehat{l}_{t} \equiv \log \left(L_{t} / L\right), \widehat{\xi}_{t} \equiv \log \left(U_{c, t} / U_{c}\right), \widehat{i}_{t} \equiv \log ((1+$ $\left.\left.i_{t}\right) /(1+\rho)\right)$, and $\widehat{\rho}_{t} \equiv-\log \left(Z_{t+1} / Z_{t}\right)$, and with $\widehat{g}_{t}=G_{t} / Y$ now, the equilibrium around the steady state can be approximated by the following system (ignoring the ZLB constraint at this point):

$$
\begin{gathered}
\widehat{y}_{t}=\widehat{c}_{t}+\widehat{g}_{t} \\
\widehat{\xi}_{t}=\widehat{\xi}_{t+1}+\left(\widehat{i}_{t}-\pi_{t+1}-\widehat{\rho}_{t}\right) \\
\widehat{\xi}_{t}=-\sigma \widehat{c}_{t}+v \widehat{l}_{t} \\
\pi_{t}=\beta \pi_{t+1}-\lambda \widehat{\mu}_{t} \\
\widehat{\mu}_{t}=\widehat{\xi}_{t}-\left(\frac{\alpha+\varphi}{1-\alpha}\right) \widehat{y}_{t} \\
\widehat{l_{t}}=\widehat{c}_{t}-\widehat{i}_{t} \\
\widehat{l}_{t-1}=\widehat{l}_{t}+\pi_{t}-\Delta m_{t} \\
\widehat{b}_{t}=\left(1+\rho-\psi_{b}\right) \widehat{b}_{t-1}+b(1+\rho)\left(\widehat{i}_{t-1}-\pi_{t}\right)+\widehat{g}_{t}-\widehat{t}_{t}^{*}-\varkappa \Delta m_{t}
\end{gathered}
$$

where $\varphi \equiv N V_{n n} / V_{n}, \sigma \equiv-C U_{c c} / U_{c}, v \equiv L U_{c l} / U_{c}$ and $\eta \equiv \epsilon_{l c} / \rho$, with $\epsilon_{l c} \equiv-\left(1 / h^{\prime}\right)(\rho /(1+\rho)) V$ denoting the elasticity of substitution between consumption and real balances, with all terms evaluated at the steady state. ${ }^{15}$ As discussed above, $\widehat{t}_{t}^{*}=-\delta^{t}$ for $t=0,1,2$,...in the case of a tax cut, and $\widehat{g}_{t}=\delta^{t}$ for $t=0,1,2, \ldots$ when an increase in government purchases is assumed instead.

In order to close the model, the above equilibrium conditions must be supplemented with an equation describing monetary policy, which in turn is determined by the financing regime assumed. As shown above, in the case of money financing, monetary policy is described by a money supply rule given by:

$$
\left.\Delta m_{t}=(1 / \varkappa)\left(\delta^{t}+b(1+\rho) \widehat{i}_{t-1}-\pi_{t}\right)\right)
$$

\footnotetext{
${ }^{13}$ Given my objectives, that choice of steady state carries little loss of generality but simplifies the algebra considerably.

${ }^{14} \mathrm{~A}$ sufficient condition for a unique steady state is given by $U_{c}(C, \varkappa C)$ being non-increasing in $C$, with $\varkappa \equiv h^{-1}(\rho /(1+\rho))$ denoting the steady state inverse velocity.

${ }^{15}$ Note that $\epsilon_{l c}=1 /\left(\sigma_{l}+v\right)$ with $\sigma_{l} \equiv-L U_{l l} / U_{l}$.
} 
Under debt financing, by contrast, monetary policy is assumed to pursue an inflation targeting mandate, implying:

$$
\pi_{t}=0
$$

for all $t$. In the latter case money growth adjusts endogenously in order to support the interest rate required to stabilize inflation, as determined by (20) and (21).

The previous model is, of course, a highly stylized one, but it contains the key ingredients for a meaningful analysis of the issue at hand. In particular, the presence of nominal rigidities makes room for monetary policy to affect real outcomes in addition to nominal ones.

\subsection{Calibration}

Unless noted otherwise, the simulations below assume the following baseline parameter settings. The discount factor is set at $\beta=0.995$, which implies a steady state (annualized) real interest rate of about 2 percent. I assume $\varphi=5$ (corresponding to a Frisch elasticity of labor supply of 0.2). Parameter $\alpha$ is set to 0.25 . These are values broadly similar to those found in the literature. As in Galí (2015), I set $\epsilon=9$, thus implying a 12.5 percent steady state price markup. I assume a baseline setting of $\theta=3 / 4$, i.e. an average price duration of four quarters, a value consistent with much of the empirical micro and macro evidence. Below I also report findings for alternative $\theta$ values, in order to stress the importance of price rigidities in generating some of the findings.

In calibrating the steady state inverse velocity $(\varkappa)$ and the interest semi-elasticity of money demand $(\eta)$ I must take a stand on the appropriate empirical counterpart to the model's money stock variable. The focus on direct financing of the fiscal stimulus through money creation by the central bank calls for choosing the monetary base (M0) as that empirical counterpart. Average (quarterly) M0 income velocity in the U.S. over the 1960-2015 period is 3.6. The corresponding value for the euro area over the period 1999-2015 is 2.7. I take a middle ground and set $\varkappa=1 / 3$ as the steady state inverse velocity in the baseline calibration. In order to calibrate the interest semi-elasticity of money demand, I rely on the evidence in Ireland (2009) using quarterly U.S. data for the period 1980-2006. Implied estimates for $\eta$ in the latter paper range between 6 and 8 (once scaled to be consistent with a quarterly interest rate), so I adopt a baseline setting of 7. Finally, in my baseline calibration I assume separability of real balances, which implies $v=0$.

I calibrate the tax adjustment parameter, $\psi_{b}$, so that one-twentieth of the deviation from target in the debt ratio is corrected over four periods (i.e. one year), in the absence of further deficits. ${ }^{16}$ This requires setting $\psi_{b}$ equal to 0.02 . That calibration can be seen as a rough approximation to the fiscal adjustment speed required for euro area countries, as established by the so-called "fiscal compact" adopted in 2012. With regard to the target debt ratio $b, \mathrm{I}$ assume a baseline setting of 2.4, which is consistent with the 60 percent reference value specified in EU agreements (after suitable scaling to quarterly output). Finally, with regard to the persistence parameter $\delta$, I choose 0.5 as a baseline setting. Results for alternative values of that parameter are reported in the sensitivity analysis section.

\footnotetext{
${ }^{16}$ Given $\rho=0.005$, as implied by the baseline calibration, $\psi_{b}$ is determined by the condition $\left(1.005-\psi_{b}\right)^{4}=$ 0.95 .
} 


\section{The Effects of a Money-Financed Fiscal Stimulus in Normal Times}

In the present section I use the basic New Keynesian model as a framework for the analysis of the effects of a tax cut and an increase in government purchases under the two financing schemes introduced above, i.e. debt and money financing.

Before undertaking that analysis, it is useful to note that, in the special case of fully flexible prices $(\theta=0)$ and separable real balances $(v=0)$, the effects of a fiscal stimulus on real variables (other than real balances) are independent of the financing method. That irrelevance result is a consequence of Ricardian equivalence, given the assumption of lump-sum taxes, combined with money neutrality, which follows from price flexibility and separability of real balances $(\theta=v=0)$. Its proof is straightforward. Under flexible prices, all firms set prices as a constant markup over marginal cost, implying $\widehat{\mu}_{t}=0$ for all $t$, which combined with (15), (17) and (19) and the assumption of separability of real balances $(v=0)$ yields:

$$
\widehat{y}_{t}=\frac{\sigma(1-\alpha)}{\alpha+\varphi+\sigma(1-\alpha)} \widehat{g}_{t}
$$

for $t=0,1,2, \ldots$ implying a government spending multiplier $\Delta \widehat{y}_{t} / \Delta \widehat{g}_{t}$ less than one, since consumption is always crowded-out in response to an increase in government purchases.

While under the above assumptions the equilibrium level of output (and, as a result, employment) is increasing in government purchases, it is independent of how those purchases are financed, since output is not affected by the path of taxes, government debt or the money supply in that case. This is also the case for consumption (given (15)) and the real interest rate $\widehat{r}_{t} \equiv \widehat{i}_{t}-\pi_{t+1}$ (given (16) and (17)). ${ }^{17}$

The previous irrelevance result no longer holds when prices are sticky and/or utility is not separable in real balances. The analysis and simulations below focus on the consequences of departing from the assumption of price flexibility for the effects of a money-financed fiscal stimulus, relative to the case of debt financing. The reason why the financing method matters in that case can be described as follows: When prices are sticky, aggregate demand and output are a function of current and expected real interest rates, which in turn are affected by the paths for the money supply and nominal interest rates. Those paths differ across financing methods. The analysis below aims at assessing the sign and size of such differential effects when a realistic degree of price stickiness is assumed. ${ }^{18}$

\footnotetext{
${ }^{17}$ Not surprisingly, the equilibrium price level (and other nominal variables) is not invariant to the financing method even in the particular case of flexible prices and separable real balances. Note that in the latter case, the equilibrium price level is the solution to the difference equation

$$
p_{t}=\frac{\eta}{1+\eta} p_{t+1}+\frac{1}{1+\eta} m_{t}+u_{t}
$$

While $u_{t} \equiv(1+\eta)^{-1}\left(\eta \widehat{r}_{t}-\widehat{c}_{t}-l\right)$ is independent of the financing method in that particular case, this is not true for $m_{t}$, and hence for the price level.

${ }^{18}$ Nonseparability of real balances $(v \neq 0)$ also breaks the irrelevance proposition, even when prices are fully flexible. In the latter case (25) holds, and the fact that different financing methods will have different effects on the path of money, inflation and nominal interest rates implies that real balances (given (20)) and, hence, output (given (25)) will also be affected by how the fiscal stimulus is financed. As discussed in Woodford (2003)
} 


\subsection{A Money-Financed Tax Cut}

Figure 1 displays the response over time of output, inflation, debt and other macroeconomic variables of interest to an exogenous tax cut, under the baseline calibration described above. ${ }^{19}$ The red lines with circles display the responses under the money financing (MF) scheme, while the blue lines with diamonds show the response under debt financing (DF). For inflation, I show both the annualized quarterly rate and the year-on-year rate. For debt, I display the percent response of real debt as well as that of the debt-output ratio.

As Figure 1 makes clear, a debt-financed tax cut has no effect on any variable, other than debt and taxes. That neutrality result is, of course, well known and a consequence of Ricardian equivalence, given my assumption of lump-sum taxes and a Ricardian fiscal policy: any shortrun tax reduction is matched by future tax increases, leaving their present discounted value unchanged, and the household's intertemporal budget constraint unaffected. ${ }^{20}$ Since no other equilibrium condition is affected by the tax cut and the increase in government debt (see (15)(21)), all variables (other than $\widehat{t}_{t}$ and $\widehat{b}_{t}$ ), both nominal and real, remain unchanged in response to the debt-financed tax cut. Since output and consumption are not altered, neither is inflation. The central bank does not have to adjust the interest rate or the money supply in order to stabilize inflation. ${ }^{21}$

On the other hand, a money-financed tax cut (or, equivalently, a money-financed increase in transfers, the experiment closer to the popular notion of a "helicopter drop") has a substantial expansionary effect on the level of economic activity, as reflected in the persistent rise in output displayed in Figure 1 (see red lines with circles). That increase is driven by the rise in consumption resulting from lower real interest rates. Output rises by about half a percentage point on impact. Inflation also rises, with the response of the year-on-year rate reaching a peak of about 0.4 percentage points four quarters after the start of the intervention. Note that by construction real debt remains unchanged under money financing, while the debt-output ratio declines in the short run due to the temporary increase in output. Interestingly, while the money supply increases in the short run as a result of the policy intervention, it decreases later during the adjustment process, due to the reduced interest expenses that result from the fall in real rates.

The previous non-neutrality result should not be surprising: the underlying experiment is not too different from a policy intervention often analyzed in the literature, namely, an increase in the money supply in an environment in which monetary policy is not neutral due to the presence of sticky prices. ${ }^{22}$ The difference lies in the fact that the money supply path in the present experiment is determined endogenously by the financing rule (8), while it is exogenous in the standard textbook experiment.

Why does the Ricardian equivalence property apply to the debt-financed tax cut but not to

and Galí (2015), among others, the non-neutralities that rely exclusively on nonseparable real balances tend to be quantitatively small and to have counterfactual implications.

${ }^{19}$ As discussed above, in the present section the ZLB constraint has been ignored in solving for the equilibrium responses.

${ }^{20}$ See the Appendix for a formal proof.

${ }^{21}$ This result does not hinge on the assumption of strict inflation targeting. In fact, it is independent of the exact monetary policy rule, as long as the latter doesn't respond to taxes or the debt ratio themselves.

${ }^{22}$ See, e.g. Galí (2015, chapter3). Fiscal policy considerations are often ignored in the analysis of such interventions in the literature. In the case of a tax cut this is at no cost, due to Ricardian equivalence. 
the money-financed one? In order to answer this question it is useful to look at the consumption function of an individual household operating in the model economy. As shown in the Appendix, under the assumption (for analytical convenience) that $U(C, L) \equiv \log C+\chi \log L$ and after substituting in the government intertemporal budget constraint (setting $G_{t}=0$, again, for simplicity), one can derive an expression for individual consumption in period 0, i.e. when the stimulus is announced:

$$
C_{0}=\frac{1-\beta}{\chi}\left[\frac{M_{-1}}{P_{0}}+\sum_{t=0}^{\infty} \Lambda_{0, t}\left(Y_{t}+\frac{\Delta M_{t}}{P_{t}}\right)\right]
$$

Note that the term in square brackets can be interpreted as the individual household's wealth (financial plus nonfinancial). Changes in the path of taxes or of debt by themselves do not affect wealth and, as a result, consumption or output. That is the well known Ricardian equivalence result. On the other hand, to the extent that the money-financed tax cut raises the discounted sum of real seignorage, $\sum_{t=0}^{\infty} \Lambda_{0, t} \Delta M_{t} / P_{t}$, current tax cuts will be perceived as net worth by each individual household (since they will not be fully offset by future tax increases), inducing and increase of individual consumption in partial equilibrium, i.e. given the initial level of output, prices and interest rates. In the presence of sticky prices, the monetary expansion will lower nominal rates (and real rates, given prices), through a conventional liquidity effect, which will enhance the initial positive wealth effect. The resulting increase in aggregate consumption, combined with the assumed stickiness of prices, will then trigger several general equilibrium effects, including an increase in output and inflation, as shown in Figure 1. In a rational expectations equilibrium, the household's perceived increase in net worth that triggered such a response will prove to be correct ex-post, thus justifying the initial increase in consumption.

On the other hand, and as discussed above, when prices are fully flexible (and utility is separable in real balances), aggregate output is not affected by the tax cut, even if the latter is money-financed. Through the lens of the household's intertemporal budget constraint we can see why: the initial jump in the price level and its subsequent trajectory exactly offsets the increase in the money supply, leaving individual households' perceived net worth unchanged, at the initial level of output an real interest rates. Formally, the term $M_{-1} / P_{0}+\sum_{t=0}^{\infty} \Lambda_{0, t} \Delta M_{t} / P_{t}$ remains unaltered. That, in turn, fails to trigger any change in consumption, individual and aggregate, leaving output (and, thus, the right hand side of the consumption function above), unchanged.

\subsection{A Money-Financed Increase in Government Purchases}

Figure 2 displays the dynamic response of the same macroeconomic variables to an exogenous increase in government purchases, under the baseline calibration introduced above and ignoring the ZLB constraint. Again, the red lines with circles display the responses under the money financing $(\mathrm{MF})$ scheme, while the blue lines with diamonds show the response under debt financing (DF).

Consider first, as a benchmark experiment, the case of a debt-financed increase in government purchases, with monetary policy pursuing an inflation targeting strategy. Note that the expansionary effects of that policy are strongly subdued, as reflected in the tiny increase in output resulting from the policy intervention. In fact, equation (25) provides an analytical 
expression for the size of the output response in this case since the equilibrium under strict inflation targeting is equivalent to that under flexible prices. Note that the multiplier is always smaller than one, since consumption unambiguously goes down as a result of higher real interest rates (needed to stabilize inflation) and higher future taxes. Debt increases moderately, returning to its initial value asymptotically, as guaranteed by the fiscal policy rule (through higher taxes). Note also that, due to Ricardian equivalence, any other tax rule (including a balanced budget one) would not alter the equilibrium responses of output and other real variables (except for $\widehat{b}_{t}$ and $\widehat{t}_{t}$ themselves).

Under money financing, by contrast, the expansionary effects on output are much larger, with the multiplier remaining above unity throughout the adjustment. The key difference is that consumption now increases due to the decline in real rates brought about by the increase in liquidity, together with the more moderate anticipated tax rises, made possible by the increased discounted seignorage. ${ }^{23}$ The expansion in output and consumption, with the consequent increase in real wages (not shown) leads to a frontloaded increase in inflation, which reinforces the expansion in aggregate demand by lowering the real rate.

Figure 3 provides a comparison of the effects of an increase in government purchases to those resulting from a tax cut, both under the money financing regime. Note that the rise of output (and inflation) is larger in the case of an increase in spending, though the opposite is true for consumption. As discussed below, the previous finding appears to be robust to alternative calibrations of some key parameters.

The above finding of a small government spending multiplier on output under tax or debt financing and an inflation targeting central bank is well known from the literature on fiscal policy in the New Keynesian model. ${ }^{24}$ But as Woodford (2011) emphasizes, the property of a small multiplier is not one that is inherent to the New Keynesian model; instead, it hinges critically on the nature of the monetary policy response to the increase in government purchases. ${ }^{25}$ The experiment above provides a clear illustration of that point. Under the debt-financing regime, the central bank's focus on inflation stabilization leads to an interest rate response that strongly offsets the increase in aggregate demand triggered by greater spending. By contrast, under the money financing scheme the central bank temporarily suspends its price stability orientation, with monetary policy providing instead ample accommodation to the fiscal expansion, and reinforcing the latter's effects on output through a reduction in real interest rates. Thus, and from a different perspective, the money-financing regime analyzed above can be viewed as an example of an environment which makes it possible for an increase in government spending to crowd-in consumption, thus leading to a multiplier above one, in a way similar to other departures from the standard New Keynesian model considered in the literature. ${ }^{26}$

\footnotetext{
${ }^{23}$ Again, see Appendix for a perspective through the household's intertemporal budget constraint.

${ }^{24}$ See Ramey (2011) for a survey of that literature.

${ }^{25}$ See also the discussion in Ascari and Rankin (2013). Two recent papers illustrate the empirical relevance of that proposition: Ilzetzki et al. (JME, 2013) show that the government spending multiplier is larger in countries and historical periods characterized by fixed exchange rates, while Klein and Linneman (2019) find a larger multiplier under the recent U.S. episode with a zero lower bound (though see Ou (2018) for an alternative conclusion).

${ }^{26}$ Including the presence of hand-to-mouth consumers (see, e.g., Galí, López-Salido and Vallés (2007)), a binding ZLB constraint (e.g., Christiano, Eichenbaum and Rebelo (2011), Eggertsson (2011)), non-separable utility in consumption and hours (e.g. Bilbiie (2011)), and a policy regime characterized by an active fiscal policy and a passive monetary policy (e.g. Davig and Leeper (2011)).
} 


\subsection{Sensitivity Analysis}

Next I discuss the sensitivity of some of the qualitative findings above regarding the effectiveness of fiscal policy. The focus is on two parameters, those measuring the degree of price stickiness and the persistence of the shock. I use the cumulative output multiplier, $(1-\delta) \sum_{t=0}^{\infty} \widehat{y}_{t}$, as a measure of the effectiveness of the policy intervention.

Figure 4 displays the cumulative output multipliers for a tax cut and an increase in government purchases as a function of $\theta$, the index of price stickiness. The big dots indicate the baseline setting of that parameter. Three observations are worth making. Firstly, the multipliers are invariant to $\theta$ in the case of a debt-financed fiscal stimulus, but strongly increasing in the case of a money-financed stimulus, both for a tax cut and an increase in government purchases. ${ }^{27}$ Secondly, the size of the multiplier for a money-financed stimulus remains above that for a debt-financed stimulus and converges to it only as prices become fully flexible. And thirdly, the size of the multiplier for a money-financed increase in government purchases is larger than that of an equally-sized money-financed tax cut, for any given degree of price stickiness.

Figure 5 displays identical multipliers as a function of $\delta$, the parameter indexing the persistence of the shock. Again, the output multiplier is independent of $\delta$ in the case of a debt-financed stimulus. In the case of a money-financed tax cut the relationship appears to be non-monotonic: the multiplier is increasing for values of $\delta$ below 0.8 , but decreasing for larger values of that parameter. In the case of an increase in government purchases, the multiplier decreases with the persistence of the shock, particularly so at high values of $\delta$. Most importantly, however, the Figure confirms the robustness to changes in the degree of shock persistence of two of the findings above: that money-financed fiscal stimuli are more effective than their debt-financed counterparts, and that the output multipliers for a money-financed increase in government purchases are larger than that of a money-financed tax cut. The robustness of the previous findings extents to alternative calibrations of other parameters, including the money demand semi-elasticity $\eta$ or the size of the steady state debt ratio $b$ (results not shown).

\section{The Effects of a Money-Financed Fiscal Stimulus in a Liquidity Trap}

This section explores the effectiveness of a money-financed fiscal stimulus in stabilizing the economy in the face of a temporary adverse demand shock. The latter is assumed to be large enough to prevent the central bank from fully stabilizing output and inflation, due to a zero lower bound (ZLB) constraint on the nominal rate. That money-financed fiscal stimulus (tax cur or increase in government purchases) is compared to two alternatives: a debt-financed fiscal stimulus and a "no fiscal response" benchmark.

Note that under the notation introduced above the ZLB constraint takes the form $\widehat{i_{t}} \geq \log \beta$ for all $t$. The baseline experiment assumes that $\widehat{\rho}_{t}=-\gamma<\log \beta$ for $t=0,1,2, \ldots T$ and $\widehat{\rho}_{t}=0$ for $t=T+1, . T+2,$. . In words, this describes a temporary adverse demand shock that brings the natural rate into negative territory up to period $T$. After period $T$, the shock

\footnotetext{
${ }^{27}$ In the case of government purchases, the finding of "full" invariance is due to the assumption of strict inflation targeting. In the presence of a more flexible rule, the multiplier can be shown to be mildly increasing in the degree of price stickiness.
} 
vanishes and the natural rate returns to its initial (positive) value. The shock is assumed to be fully unanticipated but, once it is realized, the trajectory of $\left\{\widehat{\rho}_{t}\right\}$ and the corresponding policy responses are known with certainty.

The ZLB constraint can be incorporated formally in the set of equilibrium conditions above by replacing (20) with the complementarity slackness condition:

$$
\left(\hat{i}_{t}-\log \beta\right)\left(\widehat{l}_{t}-\widehat{c}_{t}+\widehat{i}_{t}\right)=0
$$

for all $t$, where

$$
\widehat{i}_{t} \geq \log \beta
$$

is the ZLB constraint and

$$
\widehat{l}_{t} \geq \widehat{c}_{t}-\widehat{i}_{t}
$$

represents the demand for real balances.

In addition to the previous changes, in the case of the debt-financed fiscal stimulus, as well as the "no fiscal response" benchmark, condition (24) must be replaced with

$$
\left(\hat{i}_{t}-\log \beta\right) \pi_{t}=0
$$

for all $t$, together with

$$
\pi_{t}=0
$$

for $t=T+1, T+2, \ldots$ Thus, the zero inflation target is assumed to be met once the shock vanishes; until that happens the nominal rate is assumed to be kept at the ZLB, i.e. $\widehat{i}_{t}=\log \beta$, for $t=0,1,2, \ldots T .{ }^{28}$ By contrast, in the case of a money-financed fiscal stimulus, equation (23) determines the money supply for all $t$. As long as the nominal rate is positive, (29) holds with equality (but it with inequality once the nominal rate reaches the ZLB and real balances overshoot their satiation level).

Several scenarios are analyzed next, each defined by a specific combination of monetary and fiscal policy responses to the demand shock described above. I assume $\gamma=-0.01$ and $T=5$. Thus, and given $\beta=0.995$, the experiment considered corresponds to an unanticipated drop of the natural interest rate to $-2 \%$ for six quarters, and a subsequent reversion back to the initial value of $+2 \%$ (in annualized terms).

I start by considering the benchmark case of no fiscal response to the shock (i.e. $\widehat{g}_{t}=\widehat{t}_{t}^{*}=0$, for $t=0,1,2, \ldots)$ and with monetary policy described by (30) and (31), a familiar scenario which I take as a benchmark. ${ }^{29}$ The solid black line (with crosses) in Figure 6 shows the economy's response to the adverse demand shock in the absence of a fiscal response. The ZLB constraint prevents the central bank from lowering the nominal rate to match the decline in the natural rate. As a result, the adverse demand shock triggers a significant drop in output and inflation. Note also that real debt increases considerably due to the rise in real interest rates, which increases the government's financial burden. Once the natural rate returns to its usual value,

\footnotetext{
${ }^{28}$ Note that under the debt-financing regime the path of nominal and real variables after $T$ is invariant to the particular "instrument rule" that implements the inflation target. A simple rule that would guarantee its attainment is given by the Taylor-like rule $\widehat{i}_{t}=\phi_{\pi} \pi_{t}$, with $\phi_{\pi}>1$.

${ }^{29}$ As argued in Galí (2015, chapter 5) that policy corresponds to the optimal discretionary (or time-consistent) monetary policy.
} 
inflation and the output gap are immediately stabilized at their zero target, with debt gradually returning to its initial value through the (endogenous) increase in taxes, as implied by (22).

The blue line (with diamonds) and red line (with circles) show the equilibrium paths for the different variables when the fiscal authority responds to the adverse demand shock by cutting taxes, financing the resulting deficit through debt or money issuance, respectively. In either case the size of the tax cut is assumed to amount to 1 percent of steady state output, and to last for the duration of the shock $\left(\widehat{t}_{t}^{*}=-0.01\right.$, for $\left.t=0,1, \ldots 5\right)$. In the case of a debt-financed tax cut we see once again Ricardian equivalence at work, with no effects on any variable (other than taxes and debt themselves) relative to the case of no fiscal response. ${ }^{30}$ By contrast, when the tax cut is financed by money creation the impact on output and inflation is substantial, with the decline in those variables more than halved relative to the case of no fiscal response, despite the moderate size of the tax cut. The key factor behind the high effectiveness of the money-financed tax cut lies in the persistently lower real interest rate it generates, relative to the case of "no fiscal response," as captured in Figure 6. That lower real rate is ultimately brought about by a lower nominal rate once the adverse shock is gone, a consequence of the permanent increase in liquidity injected into the system in order to finance the tax cut, and which is only removed gradually according to the money-financing rule (23). The implied lower real interest rate dampens the negative impact on inflation, which in turn limits further the rise in the real rate in the short run. The previous mechanism, working through the expectations of lower interest rates down the road, is reminiscent of forward guidance policies that promise to keep interest rates low once the adverse shock vanishes (see, e.g. Eggertsson and Woodford (2013)). As argued by Woodford (2012) in the context of his discussion of a related experiment in Auerbach and Obstfeld (2005) (see literature review above), the higher levels of output and inflation under the money-financed stimulus result entirely from the implicit commitment to a lower path of interest rates in the future, independently of how that lower path is brought about. This is, of course, also true in the present model. From that perspective, the money financing rule can be interpreted as a particular way of "formalizing" or "hardening" a commitment to "lower interest rates for longer" that is the trademark of forward guidance policies. ${ }^{31}$

Figure 7 shows the corresponding effects when the fiscal authority increases government purchases by 1 per cent of steady state output in response to the adverse demand shock, and for the duration of the latter (i.e. $\widehat{g}_{t}=0.01$, for $t=0,1, \ldots 5$ ). Again, the black line with crosses displays the effects of the shock in the absence of a fiscal response. In contrast with the debt-financed tax cut analyzed earlier, we see that a debt-financed increase in government purchases, whose effects are represented by the blue line (with diamonds), is now very effective at dampening the negative effects of the adverse demand shock on output and inflation. That finding is consistent with the conclusions of Christiano et al. (2011) and Eggertsson (2011), which point to the existence of very large government spending multipliers when the ZLB is binding. The main reason for the high effectiveness of government purchases in a liquidity trap (relative to normal times) lies in the absence of a dampening response of monetary policy in the form of higher nominal rates, combined with the higher expected inflation induced by the initial expansionary impact of higher government purchases. Both features tend to reduce

\footnotetext{
${ }^{30}$ Formally, we can see this by noting that no equilibrium condition other than $(22)$ is affected by the tax cut and the resulting increase in government debt. This remains true when (27) and (30) replace (20) and (30), as it is the case in a liquidity trap.

${ }^{31}$ See also Krugman (1998) for a related discussion.
} 
real interest rates relative to an identical policy in "normal" times. When the increase in government purchases (of the same size) is money-financed (see red line with circles) its impact on output and inflation is only slightly larger than under the debt-financing case, a finding which contrasts with a much larger discrepancy in "normal times" (recall Figure 2). In the latter case the interest rate path implied by the two financing regimes was much different. The greater effectiveness of money-financing in the liquidity trap scenario can be traced to the associated lower nominal rate path once the adverse shock is gone, due to the accumulated liquidity resulting from the money-financing rule, and which is only removed gradually.

Finally, Figure 8 compares the effects of a money-financed increase in government purchases to those of a money-financed tax cut, with the case of "no fiscal response" also shown as a benchmark. Note that the effect of an increase in government purchases on output is larger than that of a tax cut, though the gap between the two is noticeably smaller than in the absence of a ZLB, as analyzed in section 6 above. The larger effect of a money-financed increase in government purchases is due to the direct effect of those purchases on aggregate demand, which more than offsets the larger decline in consumption observed under that policy, relative to the money-financed tax cut. Qualitatively, the previous pattern is similar to the one discussed in section 6 above, in the absence of a ZLB constraint. What is different now is that the smaller decline in consumption in the case of a tax cut coexists with higher real interest rates in the short run, due to greater deflation combined with the binding ZLB (which prevents the Taylor principle from operating). Interestingly, however, the impact of the higher real rates in the short run on consumption in the case of a tax cut is more than offset by their lower levels later on, which account for the higher consumption. The eventual lower real rates are associated with correspondingly lower nominal rates once the adverse demand shock has vanished, relative to the case of an increase in government purchases. This in turn a consequence of a larger accumulated liquidity, due to the greater money-financing needs caused by the higher real interest rate in the short run in the case of a tax cut (relative to the case of an increase in spending), in turn a consequence of the greater deflation, due to the smaller expansion of aggregate demand. Thus, and somewhat paradoxically, the higher real rates in the short run in the case of a money-financed tax cut end up implying a smaller decline in consumption, due to their positive impact on the liquidity accumulated over time, which is eventually reflected in lower interest rates down the road.

\section{Concluding Remarks}

The present paper has studied the effects of a money-financed fiscal stimulus, and compared them with those resulting from a conventional debt-financed stimulus, with and without a binding zero lower bound on the nominal interest rate.

A number of results from that analysis are worth stressing. First and foremost, a moneyfinanced fiscal stimulus, in the form of a tax cut or an increase in government purchases, provides a way to boost economic activity effectively, as long as prices are reasonably sticky. Such a policy has no major adverse side effects, other than a temporary mild rise in inflation. In particular, it can be designed such that debt and taxes do not need to rise, either in the short run or the long run. Furthermore, such money-financed fiscal stimuli appear to be more effective than their debt-financed counterparts. Secondly, a money-financed increase in government purchases has 
a larger output multiplier than a money-financed tax cut. Thirdly, money-financed tax cuts also appear to be more effective countercyclical policies than their debt-financed counterparts when the ZLB is binding, though in that environment the financing regime is not so important in the case of an increase in government purchases.

The money-financed fiscal interventions analyzed above raise a number of issues that are beyond the scope of the present paper. For one, such interventions are likely to be considered illegal in many jurisdictions. In particular, the fact that monetary policy is (at least temporarily) driven by the requirements of the fiscal authority may be perceived as an outright violation of the principle of central bank independence. ${ }^{32}$ Secondly, and legal issues aside, it is clear that a recurrent use of such policies would likely be a source of an inflation bias and bring about changes in individual behavior likely to undermine their effectiveness (e.g. indexation or greater price flexibility). Those considerations notwithstanding, a money-financed fiscal stimulus may still be viewed as a powerful tool that policymakers may resort to in an emergency, when all other options have failed or are exhausted. The present paper has sought to enhance our understanding of the nature of those interventions and the mechanisms through which they may be transmitted to the economy.

\footnotetext{
${ }^{32}$ Though this would arguably not be the case if the intervention was designed and called for by the central bank itself...
} 


\section{APPENDIX}

Recall the household's period budget constraint:

$$
P_{t} C_{t}+M_{t}+B_{t}=B_{t-1}\left(1+i_{t-1}\right)+M_{t-1}+W_{t} N_{t}+D_{t}-P_{t} T_{t}
$$

Letting $Y_{t} \equiv\left(W_{t} N_{t}+D_{t}\right) / P_{t}$ denote real income, and defining $\mathcal{A}_{t} \equiv\left(B_{t-1}\left(1+i_{t-1}\right)+\right.$ $\left.M_{t-1}\right) / P_{t}$, the previous constraint can be rewritten as:

$$
C_{t}+\frac{i_{t}}{1+i_{t}} L_{t}+\frac{1}{\mathcal{R}_{t}} \mathcal{A}_{t+1}=\mathcal{A}_{t}+Y_{t}-T_{t}
$$

Solving (33) forward from period zero onward and using the transversality condition $\lim _{T \rightarrow \infty} \Lambda_{0, T} \mathcal{A}_{T}=$ 0 yields

$$
\sum_{t=0}^{\infty} \Lambda_{0, t}\left(C_{t}+\frac{i_{t}}{1+i_{t}} L_{t}\right)=\mathcal{A}_{0}+\sum_{t=0}^{\infty} \Lambda_{0, t}\left(Y_{t}-T_{t}\right)
$$

where $\Lambda_{0, t} \equiv \mathcal{R}_{0}^{-1} \mathcal{R}_{1}^{-1} \ldots \mathcal{R}_{t-1}^{-1}$.

On the other hand, solving the consolidated government budget constraint (2) forward from period 0 onwards yields:

$$
\sum_{t=0}^{\infty} \Lambda_{0, t} G_{t}+\frac{B_{-1}\left(1+i_{-1}\right)}{P_{0}}=\sum_{t=0}^{\infty} \Lambda_{0, t}\left(T_{t}+\frac{\Delta M_{t}}{P_{t}}\right)
$$

where the transversality condition $\lim _{T \rightarrow \infty} \Lambda_{0, T} \mathcal{B}_{T}=0$ has been imposed, as implied by $\lim _{T \rightarrow \infty} \Lambda_{0, T} \mathcal{A}_{T}=$ 0 combined with the non-negativity constraint on money holdings.

Combining (35) and (34), we obtain:

$$
\sum_{t=0}^{\infty} \Lambda_{0, t}\left(C_{t}+\frac{i_{t}}{1+i_{t}} L_{t}\right)=\frac{M_{-1}}{P_{0}}+\sum_{t=0}^{\infty} \Lambda_{0, t}\left(Y_{t}-G_{t}+\frac{\Delta M_{t}}{P_{t}}\right)
$$

Note that each individual household takes as given the path of $\Lambda_{0, t}, Y_{t}, G_{t}, M_{t}, i_{t}$ and $P_{t}$, while choosing $C_{t}$ and $L_{t}$ for $t=0,1,2, \ldots{ }^{33}$ Equation (36) makes clear that a tax reduction financed by the issuance of debt will be matched by future tax increases, leaving their present discounted value unchanged, and the household's intertemporal budget constraint unaffected.

${ }^{33}$ In equilibrium, $C_{t}=Y_{t}$ and

$$
\begin{aligned}
\frac{M_{-1}}{P_{0}}+\sum_{t=0}^{\infty} \Lambda_{0, t} \frac{\Delta M_{t}}{P_{t}} & =\sum_{t=0}^{\infty}\left(\Lambda_{0, t}-\Lambda_{0, t+1} \frac{P_{t}}{P_{t+1}}\right) \frac{M_{t}}{P_{t}} \\
& =\sum_{t=0}^{\infty} \Lambda_{0, t}\left(1-\mathcal{R}_{t}^{-1} \frac{P_{t}}{P_{t+1}}\right) \frac{M_{t}}{P_{t}} \\
& =\sum_{t=0}^{\infty} \Lambda_{0, t}\left(\frac{i_{t}}{1+i_{t}}\right) \frac{M_{t}}{P_{t}}
\end{aligned}
$$

That equality, however, will obtain ex-post. Ex-ante each household perceives an increase in its available resources (given by the right hand side of (36)), inducing an increase in consumption and real balances (given output, prices and interest rates). 
As a result, there is no change in consumption or real balances, with no change in $\Lambda_{0, t}, Y_{t}, M_{t}$, $i_{t}$ or $P_{t}$ being required to satisfy any equilibrium condition, only the path of taxes and debt.

On the other hand, when the tax cut is financed through the issuance of money, with the consequent increase in the discounted sum of seignorage, $\sum_{t=0}^{\infty} \Lambda_{0, t}\left(\Delta M_{t} / P_{t}\right)$, that policy intervention is perceived as net worth by each individual household, since it implies that the government's intertemporal budget constraint can be satisfied with a lower discounted sum of taxes. The increase in the household perceived net worth will in turn increase its consumption, given output, prices and interest rates. The resulting increase in aggregate consumption, combined with the assumed stickiness of prices, will then trigger a variety of general equilibrium effects, including an increase in output, inflation and interest rates.

To further illustrate the channel through which the money financed tax cut end up raising consumption, assume for simplicity $U(C, L) \equiv \log C+\chi \log L$. In that case money demand satisfies $\chi C_{t}=\frac{i_{t}}{1+i_{t}} L_{t}$ and we can rewrite (36) as

$$
\sum_{t=0}^{\infty} \Lambda_{0, t} C_{t}=\frac{1}{1+\chi}\left(\frac{M_{-1}^{H}}{P_{0}}+\sum_{t=0}^{\infty} \Lambda_{0, t}\left(Y_{t}-G_{t}+\frac{\Delta M_{t}}{P_{t}}\right)\right)
$$

Furthermore, and ignoring preference shocks, the household's Euler equation implies $\Lambda_{0, t}=$ $\beta^{t}\left(C_{0} / C_{t}\right)$ for $t=0,1,2, \ldots$ thus yielding the consumption function:

$$
C_{0}=\frac{1-\beta}{1+\chi}\left(\frac{M_{-1}}{P_{0}}+\sum_{t=0}^{\infty} \Lambda_{0, t}\left(Y_{t}-G_{t}+\frac{\Delta M_{t}}{P_{t}}\right)\right)
$$

which makes clear how an increase in current and future seignorage $\left\{\Delta M_{t} / P_{t}\right\}$ that is not fully offset by an increase in the current price level, $P_{0}$, expands the individual household's perceived resources, leading to an increase in current consumption, given the path of output, prices, interest rates, and government purchases. Given price stickiness the resulting increase in demand is reflected in an increase in output, which will further the initial increase in consumption. 


\section{References}

Ascari, G., Rankin N., 2013. The Effectiveness of Government Debt for Demand Management: Sensitivity to Monetary Policy Rules. Journal of Economic Dynamics and Control 37, 1544-1566.

Auerbach, A.J., Obstfeld, M., 2005. The Case for Open-Market Purchases in a Liquidity Trap. American Economic Review 95(1), 110-137.

Bernanke, B., 2002. Making Sure 'It' Doesn't Happen Here. Speech before the National Economists Club, Washington, D.C.

Bernanke, B., 2003. Some Thoughts on Monetary Policy in Japan. Speech before the Japan Society of Monetary Economics, Tokyo.

Bilbiie, F., 2011. Nonseparable Preferences, Frisch Labor Supply, and the Consumption Multiplier of Government Spending: One Solution to a Fiscal Policy Puzzle. Journal of Money, Credit and Banking 43(1), 221-251.

Bilbiie, F., Ragot, X. (2017). Optimal Monetary Policy and Liquidity with Heterogeneous Households. Unpublished manuscript.

Buiter, W.H., 2014. The Simple Analytics of Helicopter Money: Why it Works - Always. Economics E-Journal 8, 1-51.

Christiano, L., Eichenbaum, M., Rebelo, S., 2011. When is the Government Spending Multiplier Large?. Journal of Political Economy 119(1), 78-121.

Davig, T., Leeper E.M., 2011. Monetary-Fiscal Policy Interactions and Fiscal Stimulus. European Economic Review 55, 211-227.

Eggertsson, G., 2011. What Fiscal Policy is Effective at Zero Interest Rates?. NBER Macroeconomics Annual 2010, 59-112.

Eggertsson, G., Ferrero A., Raffo, A., 2014. Can Structural Reforms Help Europe?. Journal of Monetary Economics 61, 2-22.

Eggertsson, G., Woodford, M., 2003. Zero Bound on Interest Rates and Optimal Monetary Policy. Brookings Papers on Economic Activity 2003(1), 139-233.

Friedman, M., 1948. A Monetary and Fiscal Framework for Economic Stability. American Economic Review 38(3), 245-264.

Friedman, M., 1969. The Optimum Quantity of Money. In: The Optimum Quantity of Money and Other Essays, Aldine Press (Chicago, IL).

Galí, J., López-Salido, J.D., Vallés, J., 2007. Understanding the Effects of Government Spending on Consumption. Journal of the European Economics Association 5(1), 227-270.

Galí, J., 2013. Notes for a New Guide to Keynes (I): Wages, Aggregate Demand and Employment. Journal of the European Economic Association, 11(5), 973-1003.

Galí, J., 2015. Monetary Policy, Inflation and the Business Cycle: An Introduction to the New Keynesian Framework, Second edition, Princeton University Press (Princeton, NJ).

Galí, J., Monacelli, T., 2016. Understanding the Gains from Wage Flexibility: The Exchange Rate Connection. American Economic Review 106(12), 3829-3868.

Giavazzi, F., Tabellini, G., 2014. How to Jumpstart the Eurozone Economy. www.voxeu.org

Haberler, G., 1952. The Pigou Effect Once More. Journal of Political Economy, 240-246.

Ilzetzki, E., Mendoza, E., Vegh, C., 2013. How Big (Small?) are Fiscal Multipliers?. Journal of Monetary Economics 60, 239-254. 
Ireland, P.N., 2009. On the Welfare Cost of Inflation and the Recent Behavior of Money Demand. American Economic Review 99(3), 1040-1052.

Jung, T., Teranishi, Y., Watanabe, T., 2005. Optimal Monetary Policy at the Zero Interest Rate Bound. Journal of Money, Credit and Banking 37(5), 813-835.

Klein, M., Linnemann, L., 2019. Macroeconomic Effects of Government Spending: The Great Recession was (Really) Different. Journal of Money, Credit and Banking 51, 1237-1264

Krugman, P., 1998. It's Baaack: Japan's Slump and the Return of the Liquidity Trap. Brookings Papers on Economic Activity 1998(2), 137-205

Leeper, E.M., 1991. Equilibria under 'active'and 'passive'monetary and fiscal policies. Journal of Monetary Economics 27(1), 129-147.

Ou, S., 2018. The Government Spending Multiplier at the Zero Lower Bound. Unpublished manuscript.

Ramey, V., 2011. Can Government Purchases Stimulate the Economy? Journal of Economic Literature 49(3), 673-685.

Reichlin, L., Turner, A., Woodford M., 2013. Helicopter Money as a Policy Option. www.voxeu.org

Turner, A., 2013. Debt, Money, and Mephistopheles: How do we Get Out of this Mess?. Lecture delivered at the Cass Business School.

Turner, A., 2016. Between Debt and the Devil. Money, Credit and Fixing Global Finance. Princeton University Press.

Werning, I., 2011. Managing a Liquidity Trap: Monetary and Fiscal Policy. NBER WP 17344

Woodford, M., 1996. Control of the Public Debt: A Requirement for Price Stability. NBER WP\#5684.

Woodford, M., 2003. Interest and Prices: Foundations of a Theory of Monetary Policy. Princeton University Press (Princeton, NJ).

Woodford, M., 2011. Simple Analytics of the Government Spending Multiplier. American Economic Journal; Macroeconomics, 3, 1-35.

Woodford, M., 2012. Methods of Policy Accommodatin at the Interest Rate Lower Bound. In: The Changing Policy Landscape, Economic Policy Symposium Proceedings, Federal Reserve Bank of Kansas City, 185-288. 

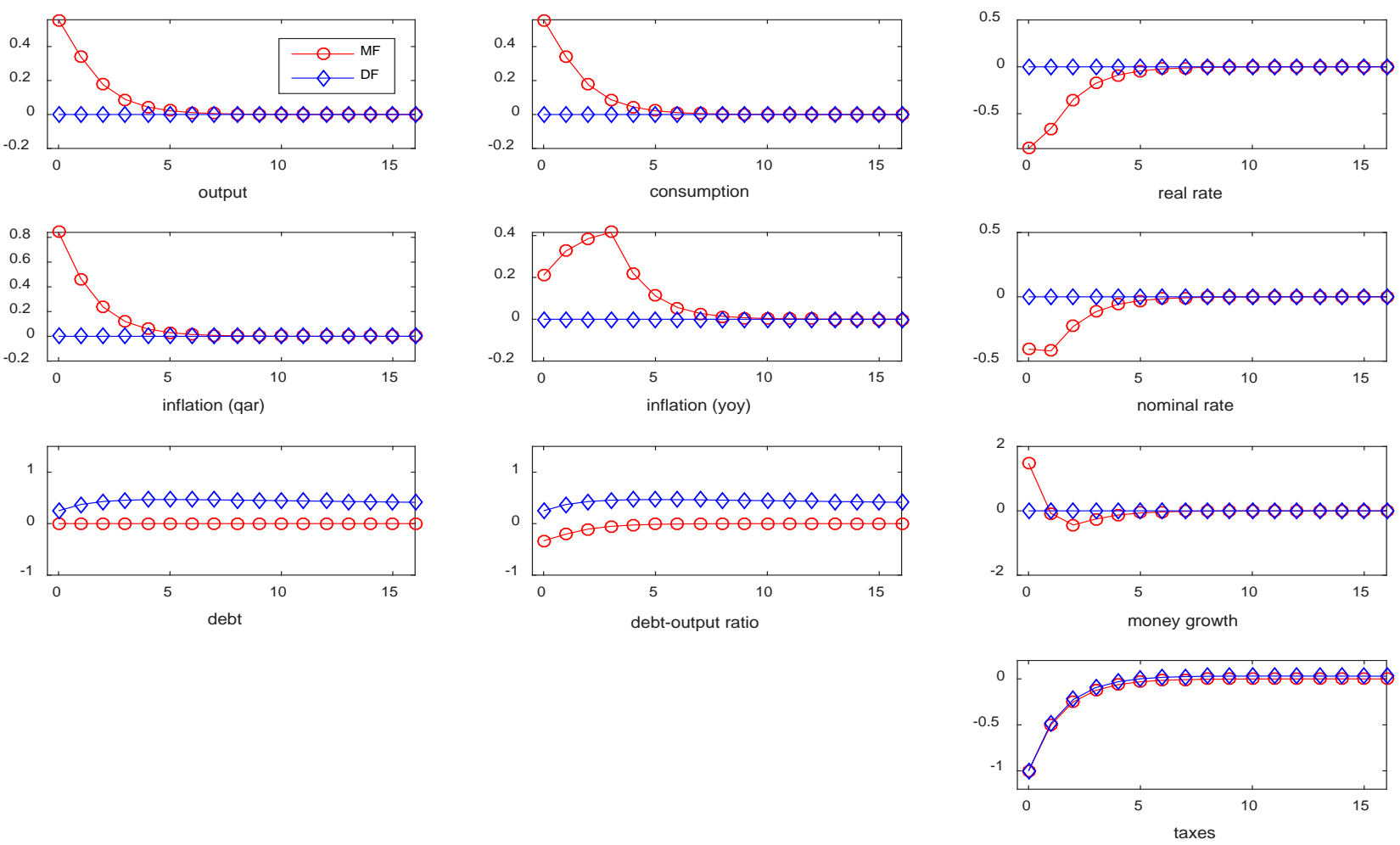

Figure 1. Dynamic Effects of a Tax Cut: Debt vs. Money Financing

Note: the figure displays the response over time of several variables to an exogenous tax cut, under the baseline calibration described in the text. The red lines with circles display the responses under the money financing (MF) scheme, while the blue lines with diamonds show the response under debt financing (DF). 

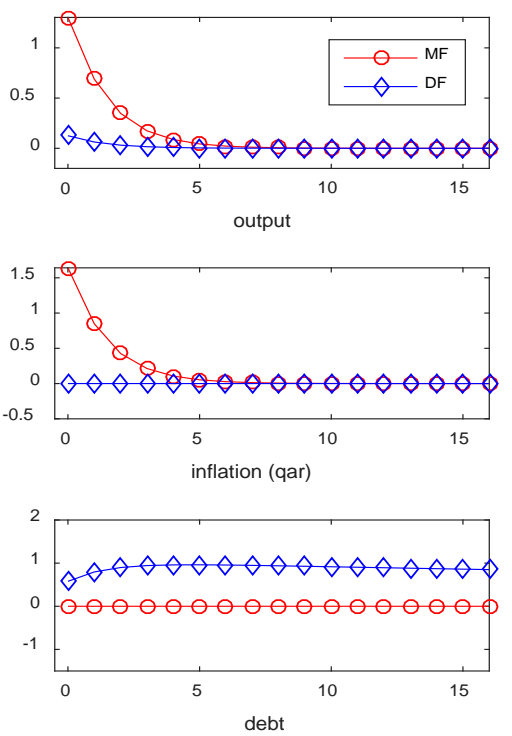

debt
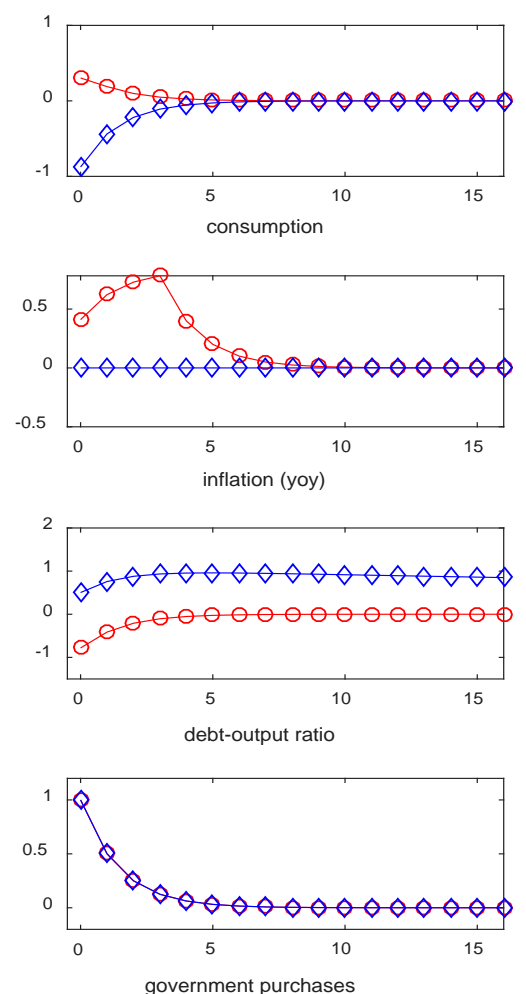
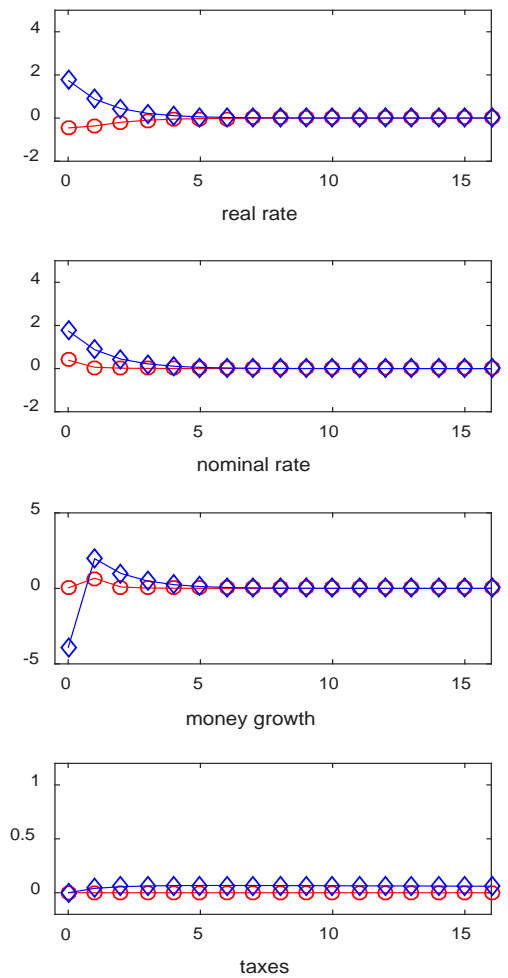

Figure 2. Dynamic Effects of an Increase in Government Purchases:

Debt vs. Money Financing

Note: the figure displays the response over time of several variables to an exogenous increase in government purchases, under the baseline calibration described in the text. The red lines with circles display the responses under the money financing (MF) scheme, while the blue lines with diamonds show the response under debt financing (DF). 

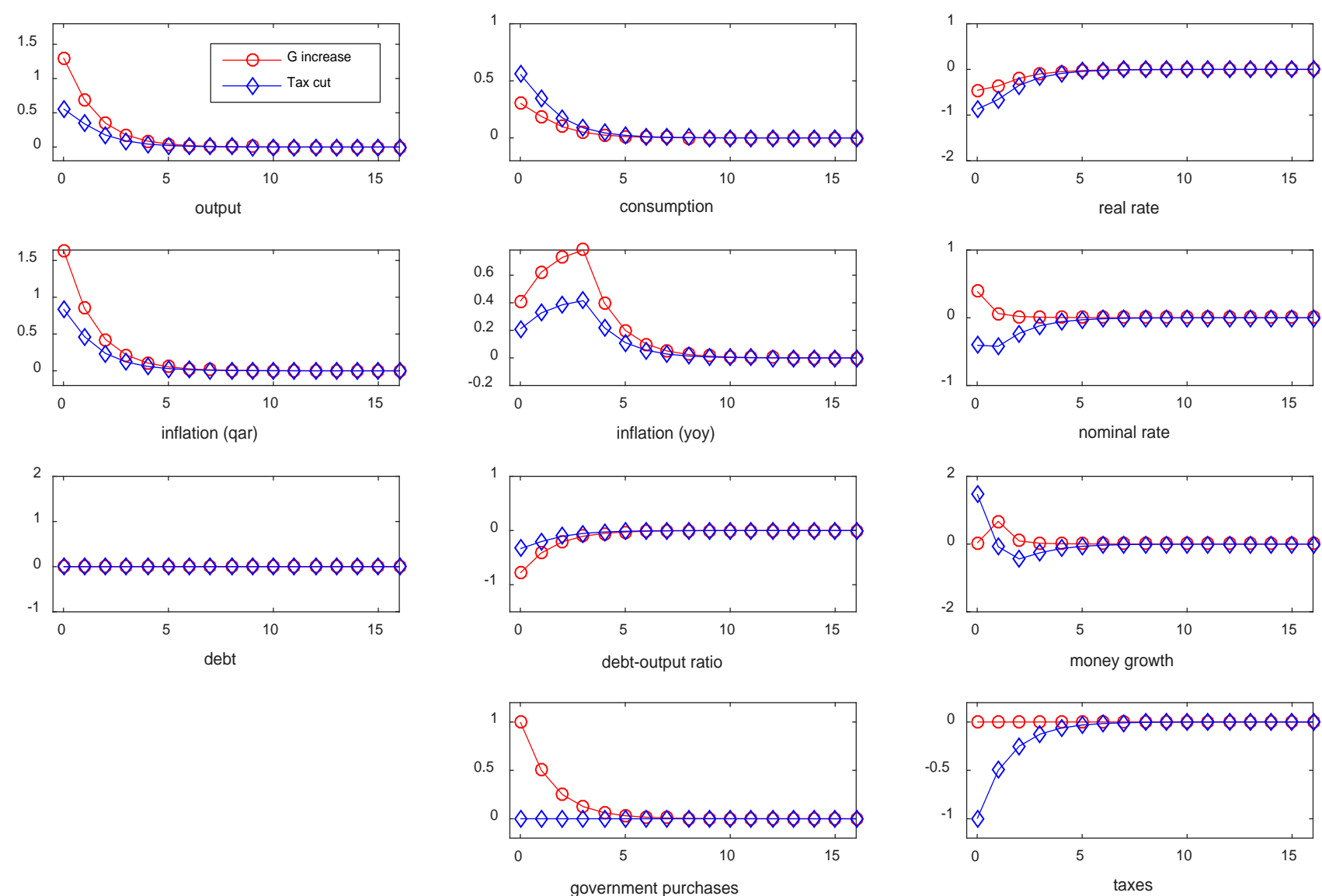

Figure 3. Dynamic Effects of Money-Financed Fiscal Stimuli: Tax cut vs. Increase in Government Purchases

Note: the figure displays the response over time of several variables to a money financed tax cut (blue lines with diamonds) and an increase in government purchases (red line with circles), under the baseline calibration described in the text. 


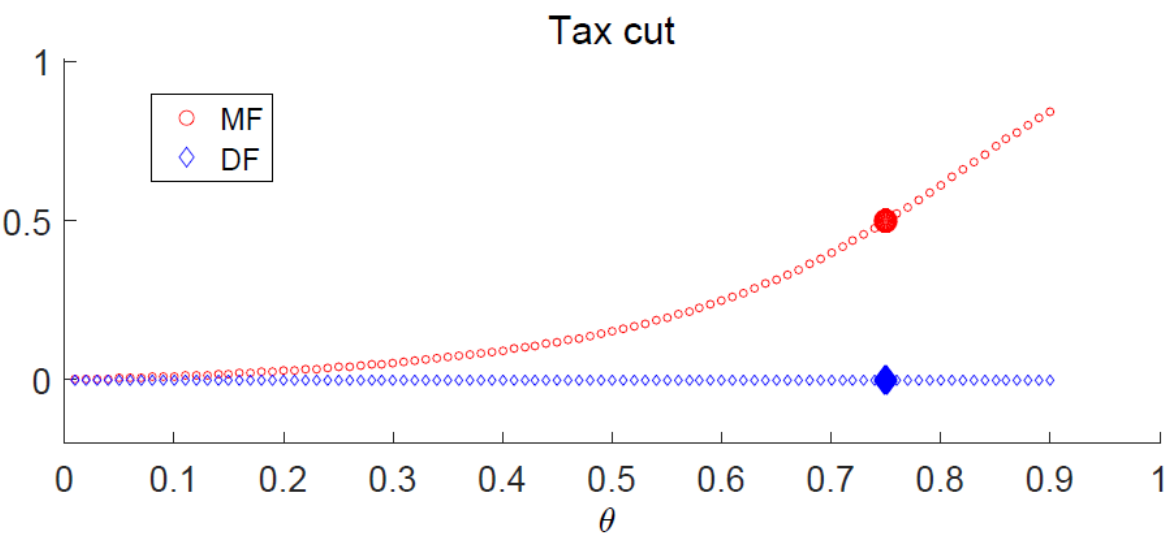

Increase in $\mathrm{G}$

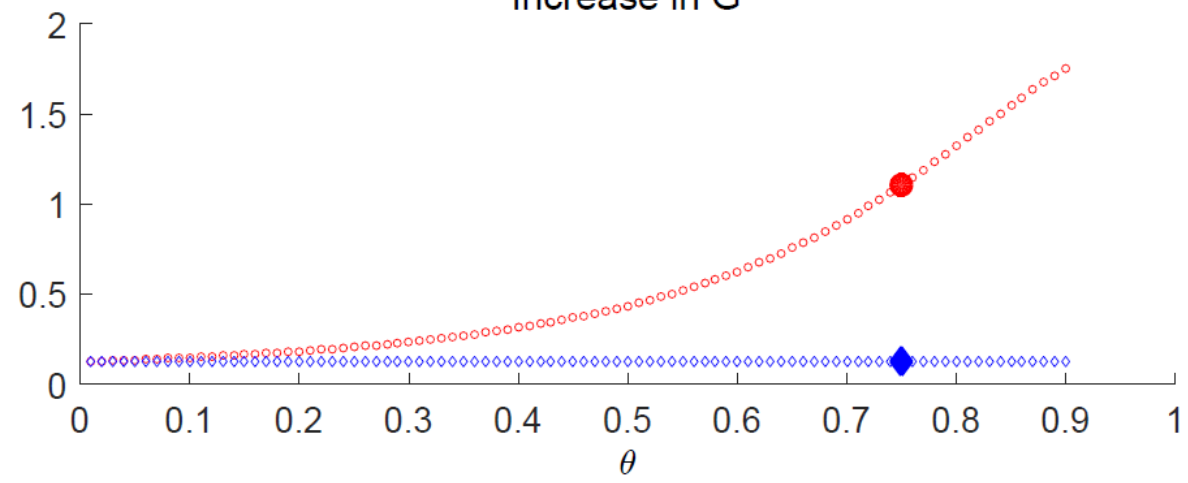

Figure 4. Fiscal Multipliers: The Role of Price Stickiness

Note: the Figure reports the value of the dynamic fiscal multiplier described in the text for a tax cut (top figure) and an increase in government purchases (bottom figure), as a function of the degree of price stickiness $\theta$. For each case the red line corresponds to a money-financing regime, while the blue line corresponds to a debt-financing regime, as described in the text. 

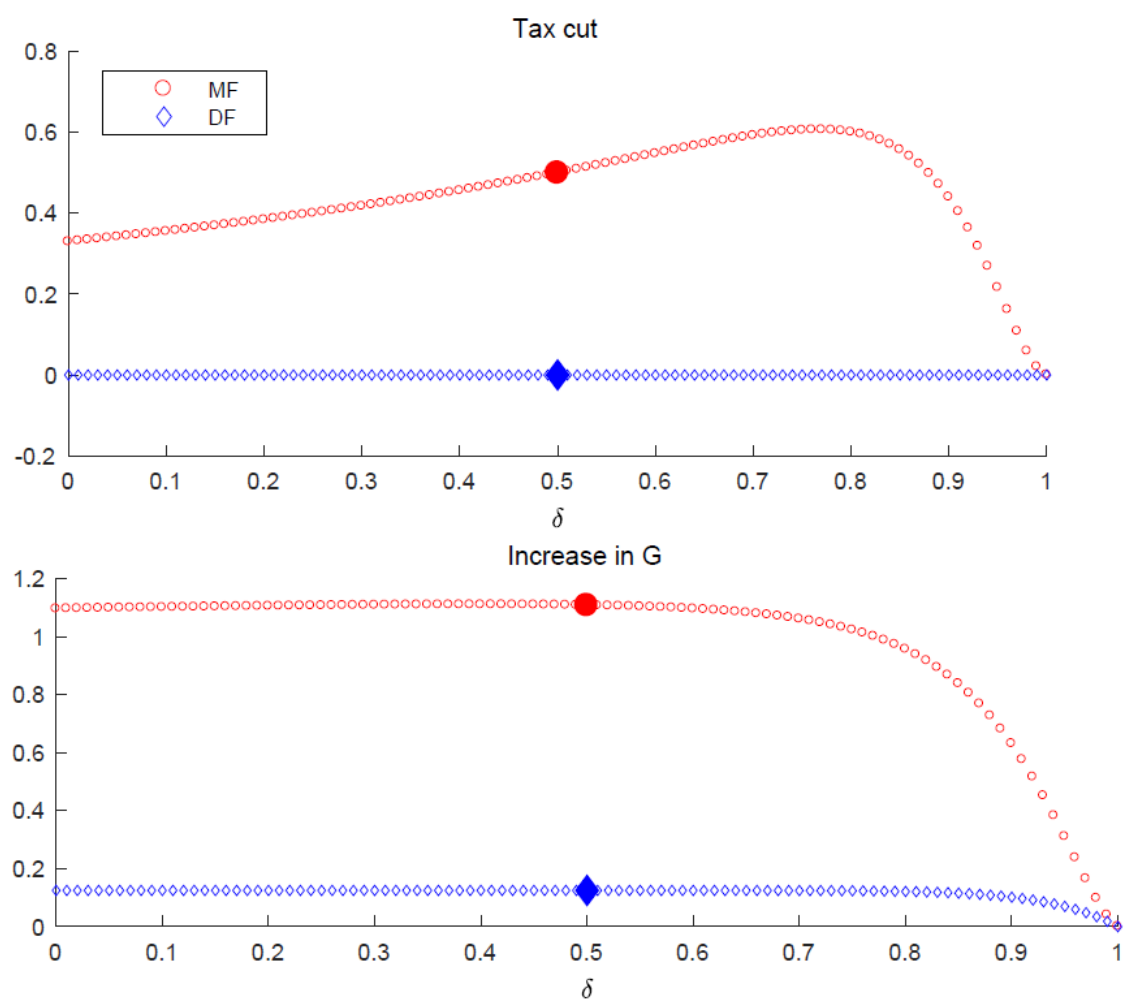

Figure 5. Fiscal Multipliers: The Role of Shock Persistence

Note: the Figure reports the value of the dynamic fiscal multiplier described in the text for a tax cut (top figure) and an increase in government purchases (bottom figure), as a function of the shock persistence $\delta$. For each case the red line corresponds to a money-financing regime, while the blue line corresponds to a debt-financing regime, as described in the text. 

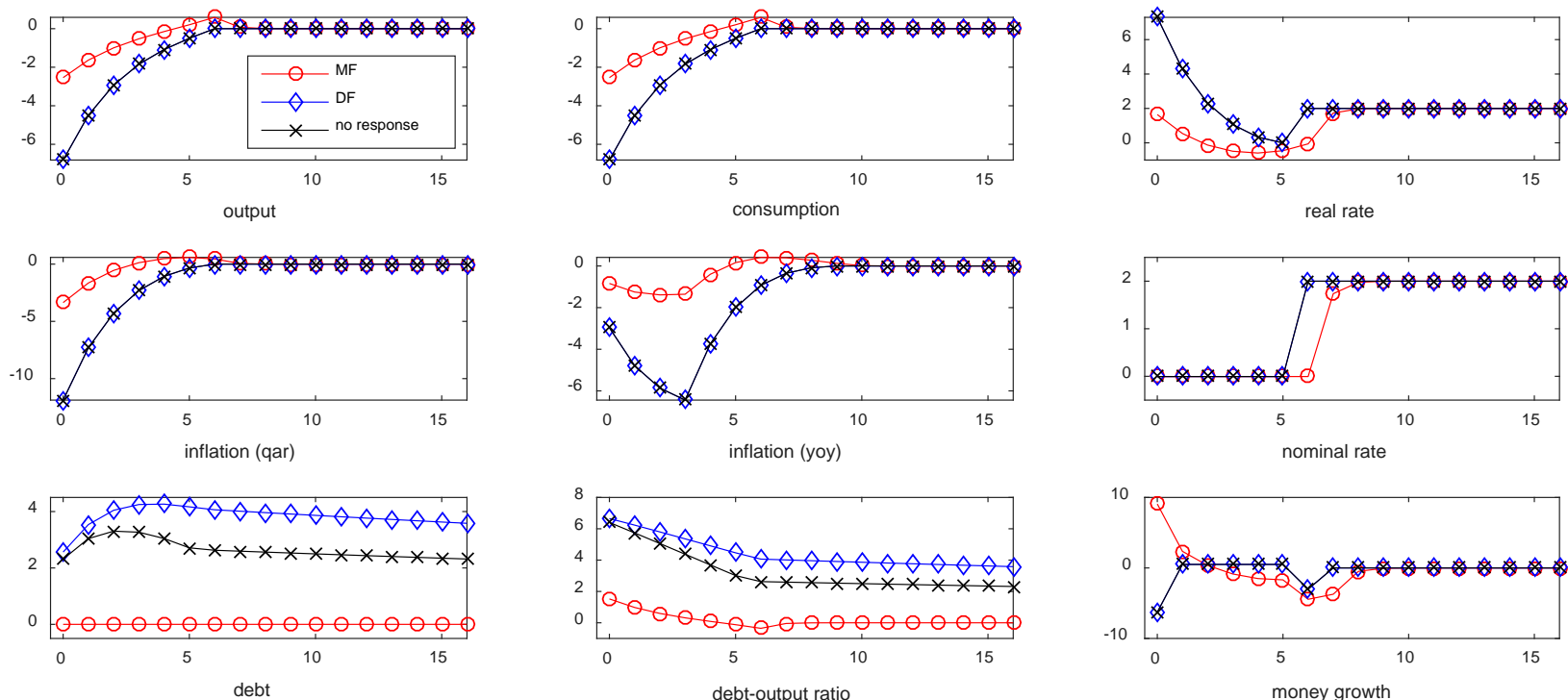

debt-output ratio

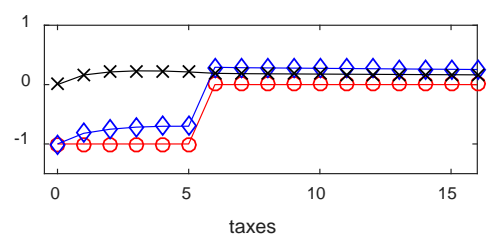

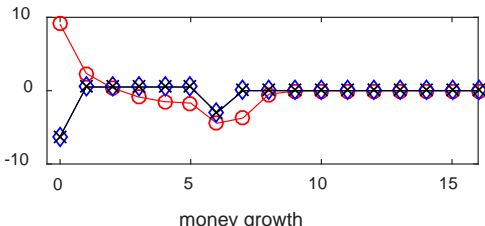

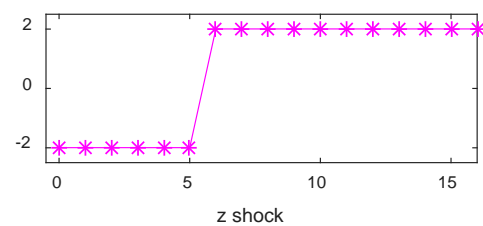

Figure 6. Dynamic Effects of a Tax Cut in a Liquidity Trap

Note: the figure displays the responses of several macro variables to an adverse demand shock that is counteracted by means of a debt-financed tax cut (blue line with diamonds) or a money-financed tax cut (red line with circles). The black line with crosses represents the equilibrium paths in the absence of a fiscal response. 

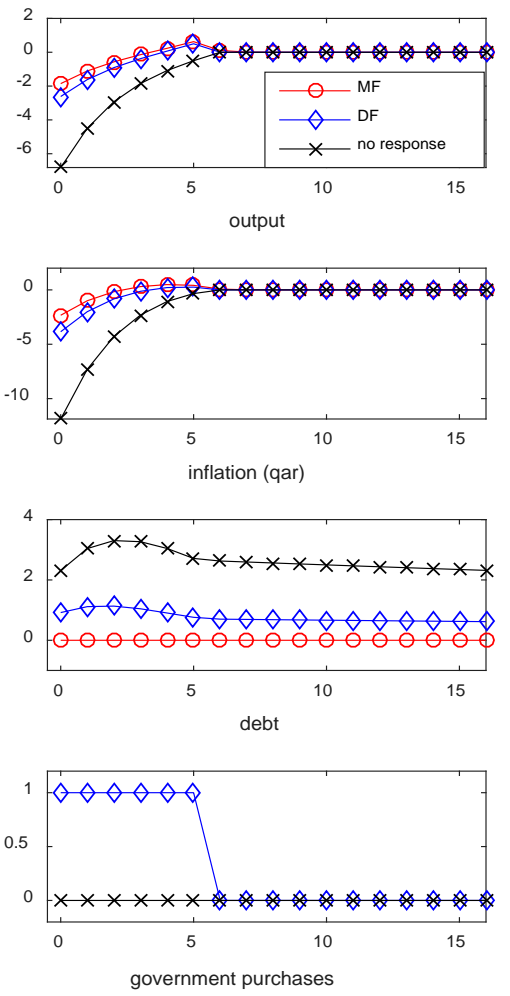
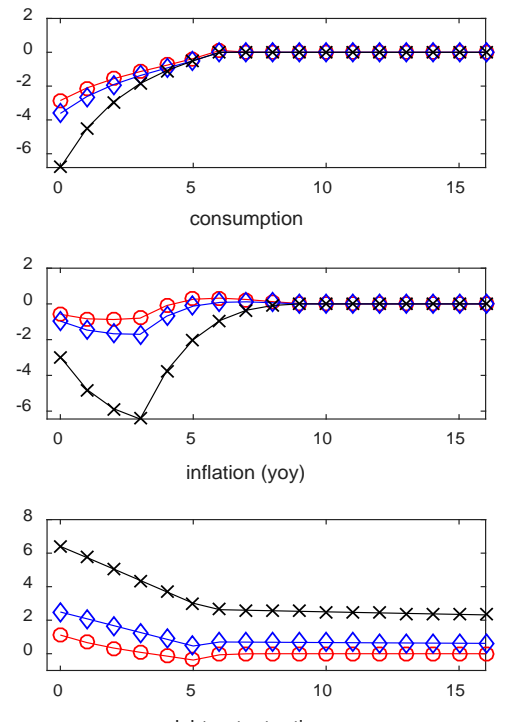

debt-output ratio

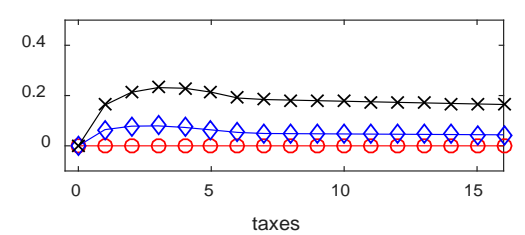

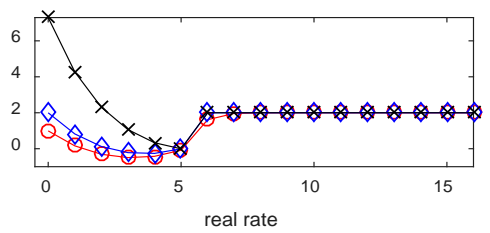
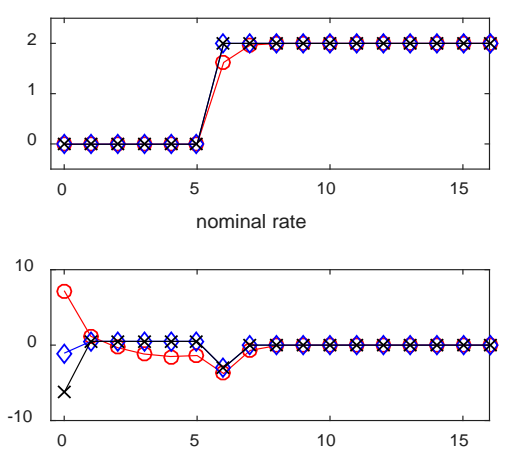

money growth

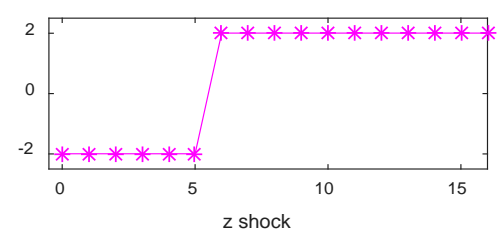

Figure 7. Dynamic Effects of an Increase in Government Purchases in a

\section{Liquidity Trap}

Note: the figure displays the responses of several macro variables to an adverse demand shock that is counteracted by means of an increase in government purchases, debt-financed (blue line with diamonds) or a money-financed (red line with circles). The black line with crosses represents the equilibrium paths in the absence of a fiscal response. 

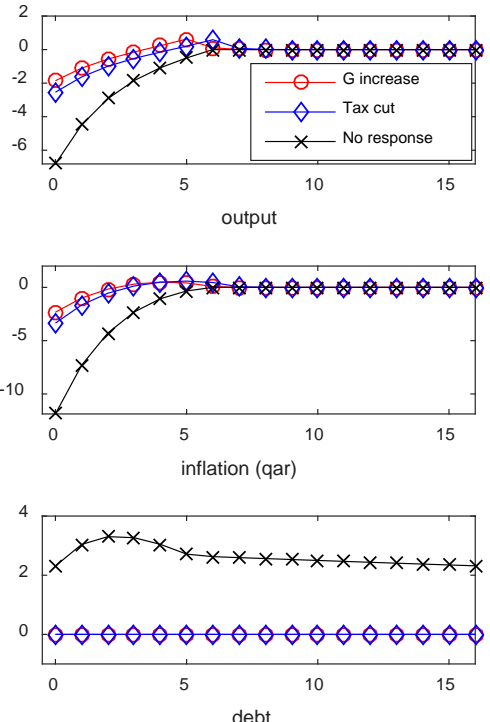

debt

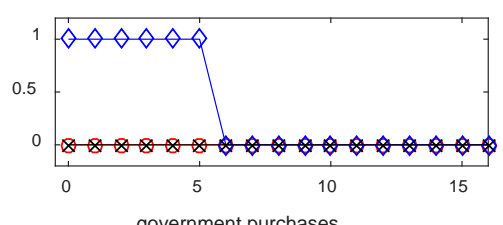

government purchases
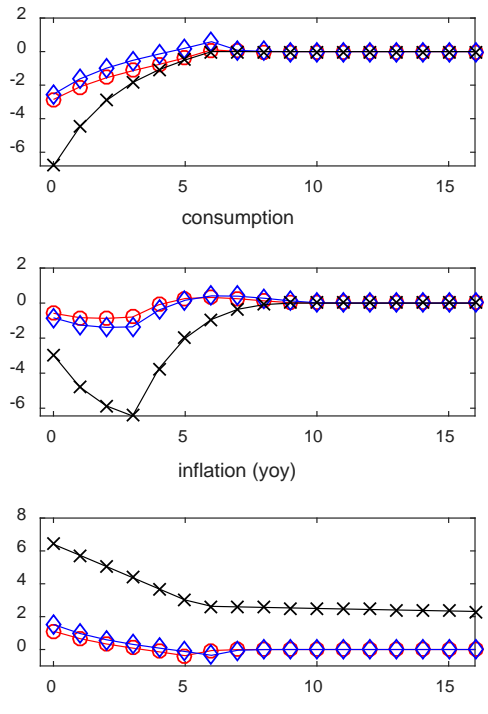

debt-output ratio

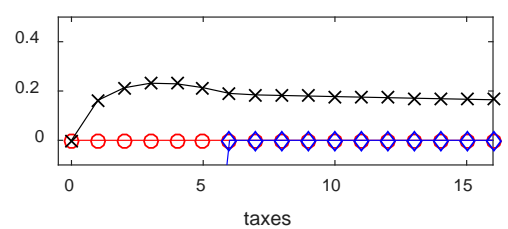

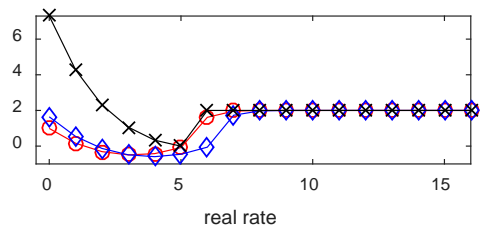
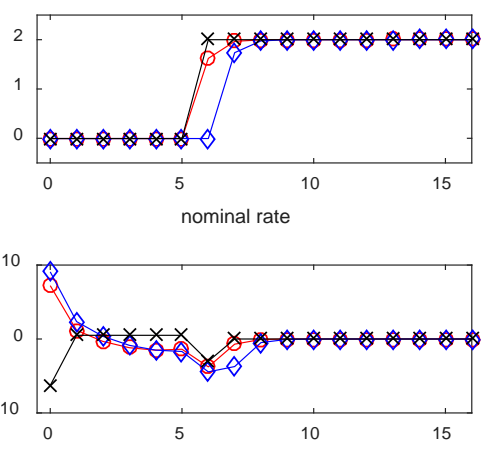

money growth

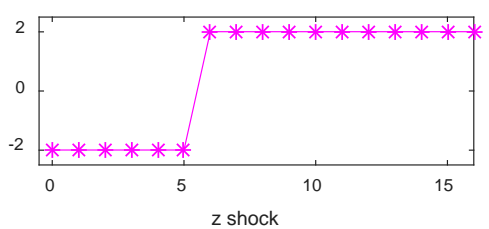

Figure 8. Dynamic Effects of Money-Financed Fiscal Stimuli in a Liquidity Trap

Note: the figure compares the responses of several macro variables to an adverse demand shock that is counteracted by means of a money-financed tax cut (blue line with diamonds) or a money-financed increase in government purchases (red line with circles). The black line with crosses represents the equilibrium paths in the absence of a fiscal response. 